\title{
Hydrocephalus: the role of cerebral aquaporin-4 channels and computational modeling considerations of cerebrospinal fluid
}

\author{
Bhargav Desai, BS, ${ }^{1}$ Ying Hsu, MS, ${ }^{2}$ Benjamin Schneller, BS, ${ }^{2}$ Jonathan G. Hobbs, MD, ${ }^{3}$ \\ Ankit I. Mehta, MD, ${ }^{1}$ and Andreas Linninger, $\mathrm{PhD}^{1,2}$
}

Departments of ${ }^{1}$ Neurosurgery and ${ }^{2}$ Bioengineering, University of Illinois at Chicago; and ${ }^{3}$ Section of Neurosurgery, University of Chicago, Illinois

\begin{abstract}
Aquaporin-4 (AQP4) channels play an important role in brain water homeostasis. Water transport across plasma membranes has a critical role in brain water exchange of the normal and the diseased brain. AQP4 channels are implicated in the pathophysiology of hydrocephalus, a disease of water imbalance that leads to CSF accumulation in the ventricular system. Many molecular aspects of fluid exchange during hydrocephalus have yet to be firmly elucidated, but review of the literature suggests that modulation of AQP4 channel activity is a potentially attractive future pharmaceutical therapy. Drug therapy targeting AQP channels may enable control over water exchange to remove excess CSF through a molecular intervention instead of by mechanical shunting. This article is a review of a vast body of literature on the current understanding of AQP4 channels in relation to hydrocephalus, details regarding molecular aspects of AQP4 channels, possible drug development strategies, and limitations. Advances in medical imaging and computational modeling of CSF dynamics in the setting of hydrocephalus are summarized. Algorithmic developments in computational modeling continue to deepen the understanding of the hydrocephalus disease process and display promising potential benefit as a tool for physicians to evaluate patients with hydrocephalus.
\end{abstract}

http://thejns.org/doi/abs/10.3171/2016.7.FOCUS16191

KEY WORDS hydrocephalus; aquaporin-4; AQP4; computational modeling; reconstruction; pharmaceutical; therapy; treatment; diagnosis

A QUAPORIN-4 (AQP4) channels are transmembrane proteins that facilitate water transport in the brain. AQP4 channels are present throughout the brain, specifically concentrated in the end-feet of astrocytes and in the glia limitans interna and externa. ${ }^{15,53,92}$ They passively respond to osmotic gradients and play roles in fluid secretion, cell migration, brain edema, metabolism, and many aspects of cell homeostasis. ${ }^{135}$ In addition to their role in brain water transport, AQP4 channels have also been increasingly linked to clearance of ions, metabolites, and even soluble proteins.$^{57}$ In the brain, AQP4 channels have been implicated in a variety of pathological processes, including traumatic brain injury, ischemic injury, vasogenic and cytotoxic cerebral edema, and hydrocephalus. ${ }^{64,65,105,110,129}$

In hydrocephalus, impaired fluid homeostasis leads to CSF accumulation in the ventricular system, which causes a variety of progressive or abrupt symptoms in patients. AQP4 channels are implicated in the pathophysiology of hydrocephalus, but their function is not sufficiently understood as a therapeutic target to manage hydrocephalus. The current treatment of choice for hydrocephalus is often limited to mechanical diversion of excess CSF. However, these strategies have many inherent complications. Ventriculoperitoneal shunts have a 5-year complication rate of $32 \%$, and an overall failure rate (requiring shunt revision) of $46.3 \%$. $^{109,139}$

For these reasons, modulating activity of AQP4 channels (to target CSF clearance) is an attractive therapeutic target for potential future pharmacological treatment of hydrocephalus. It is imperative that the complex mechanisms of brain water homeostasis be elucidated to appropriately develop these therapeutic molecular targets. ${ }^{3,8}$ AQP channels have a firmly established role in cerebral water ho-

ABBREVIATIONS AQP1 = aquaporin-1; AQP4 = aquaporin-4; AP-1 = activating protein-1; $\mathrm{BBB}=$ blood-brain barrier; $\mathrm{CK}-2$ = casein kinase-2; ICP = intracranial pressure; mGluR-I = group I glutamate receptor; PKA, PKC, PKG = protein kinase $A, C, G$.

SUBMITTED May 1, 2016. ACCEPTED July 7, 2016.

INCLUDE WHEN CITING DOI: 10.3171/2016.7.FOCUS16191. 


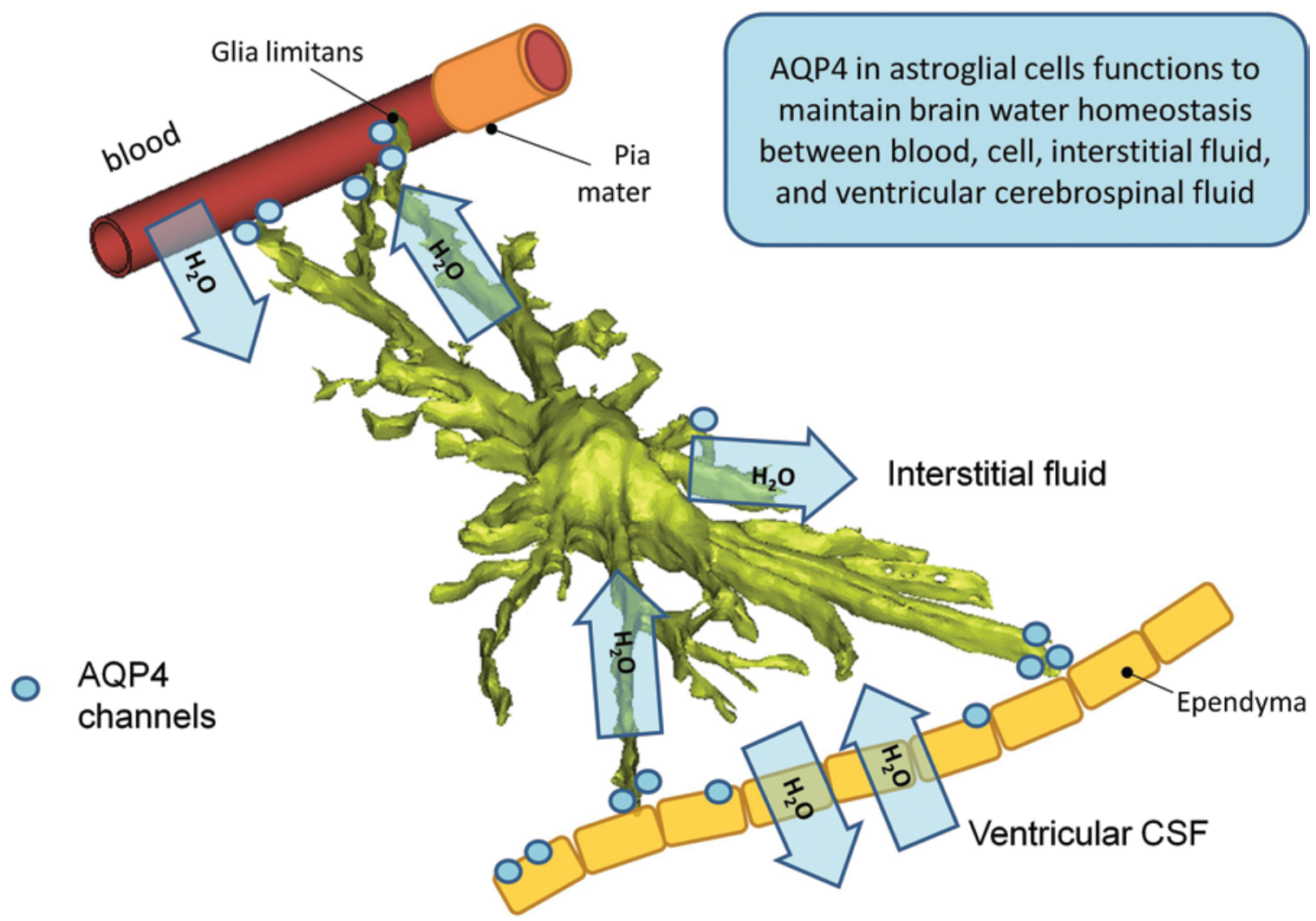

FIG. 1. An illustration of hypothesized water transport in normal conditions via AQP4 channels in astroglial cells. The astrocyte is reconstructed from a stack of confocal images (using Mimics reconstruction software).

meostasis; in fact, RNAi knockdown of AQP4 was shown to lead to a $50 \%$ reduction in water diffusion at a cellular level as measured by diffusion-weighted imaging (via apparent diffusion coefficient measurements). ${ }^{10,45,53,91,121}$

Therefore, we have attempted to summarize relevant knowledge of molecular mechanisms of water exchange through AQP4 channels. We begin with an analysis of the current research on the relationship of AQP4 to hydrocephalus, followed by an overview of AQP4 isoforms, promoters, transcription factors, and posttranslational modification. Based on this molecular review of aquaporin channels, we have summarized research on AQP4 as a therapeutic target. We review prior efforts and now present new concepts on improving computational modeling of hydrocephalus as a route to improve diagnosis.

\section{Aquaporin-4 and Hydrocephalus}

Hydrocephalus is characterized by an accumulation of CSF in brain ventricles, which may be caused by either CSF overproduction or impaired CSF absorption. In either case, AQP water channels may be involved in the pathogenesis of the disease due to their role in fluid homeostasis. Aquaporin-1 (AQP1) channels are found on epithelial cells in the choroid plexus, and serve in CSF secretion. AQP4, AQP-5, and AQP-9 channels are localized on astrocytes and ependymal cells. ${ }^{11}$ More specifically, AQP4 is present on astrocytic end-feet processes (adjacent to brain vasculature, the blood-brain barrier $[\mathrm{BBB}]$ and bloodCSF barriers), glia limitans interna (astrocyte/ependyma bordering brain and subarachnoid CSF), and glia limitans externa (astrocyte bordering brain and ventricular CSF). ${ }^{11}$

Bloch and Manley proposed a transparenchymal pathway of water clearance into the cerebral vasculature in obstructive hydrocephalus, observing an increase in water content in the parenchymal extracellular space in Aqp4null mice in addition to the increase in lateral ventricle size in these mice. ${ }^{15}$ This evidence suggests that AQP4 channels play a role in water clearance in obstructive hydrocephalus from both the ventricle and brain extracellular spaces. Figures 1 and 2 illustrate a hypothesis of AQP4 function in cerebral water transport in normal conditions and in hydrocephalus; water flux is shown with arrows. The astrocyte is reconstructed from a stack of confocal images (using Mimics reconstruction software). AQP4 channels appear to be implicated in brain homeostasis and in central plasma osmolarity regulation. ${ }^{11}$

AQP4-mediated water transport may be employed in hydrocephalus to remove excess CSF, as shown in Fig. 2. The location-specific distribution of AQP4 around "tissue interfaces that are close to CSF and thus water (ventricles, subarachnoid space)" along with the distribution of AQP4 adjacent to the BBB indicates that these channels play a role in water regulation physiology applicable to hydrocephalus. ${ }^{37}$ Mobasheri et al. used protein and tissue microarrays to show abundant human tissue AQP4 expression in the cerebral cortex, cerebellar cortex, ependymal cell layer, hippocampus, and spinal cord, but lower levels in the choroid plexus, white matter, and meninges; these findings 


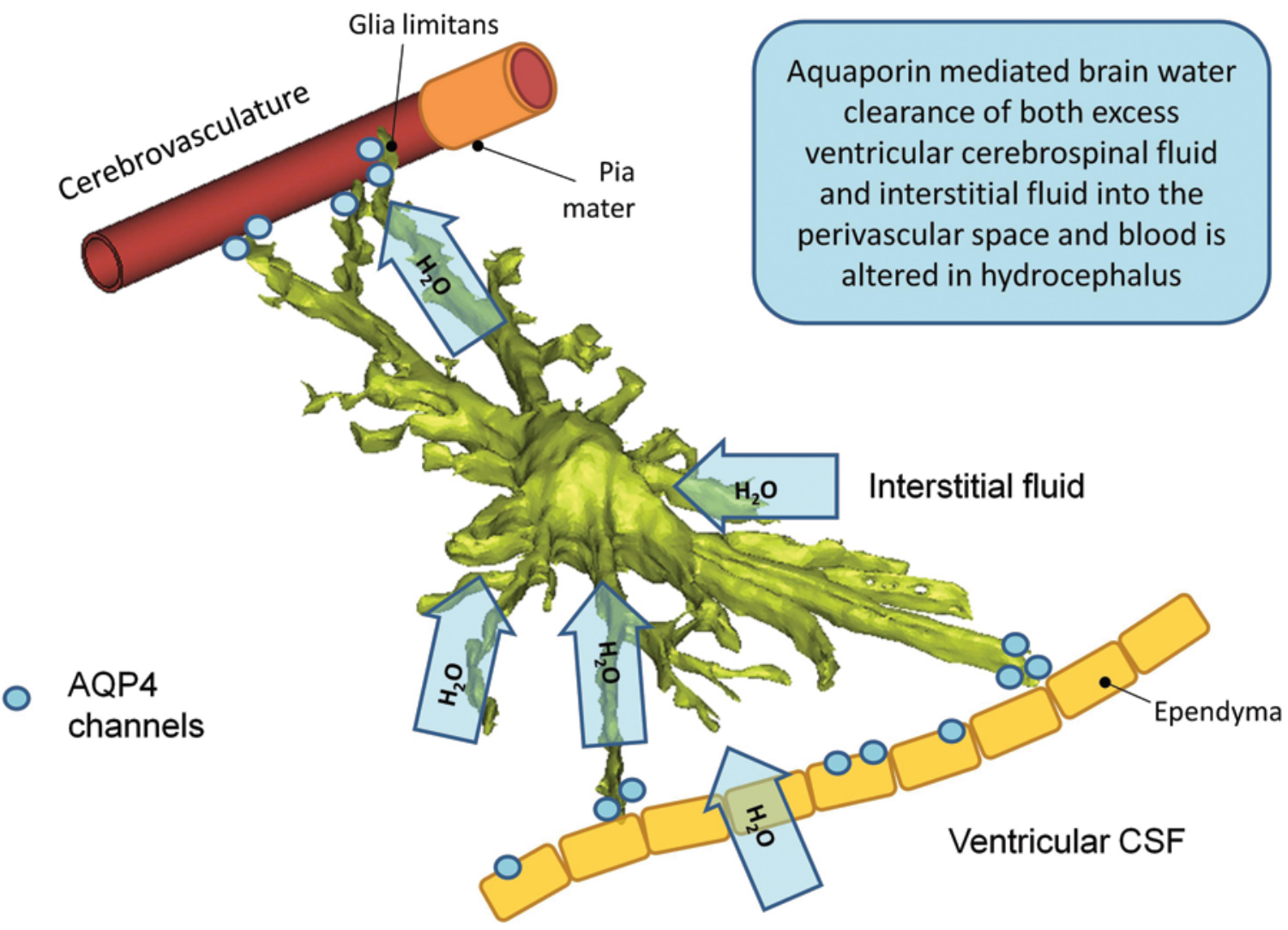

FIG. 2. An illustration of hypothesized water transport in hydrocephalic conditions, allowing for clearance of excess CSF from the ventricular system via AQP4 channels in astroglial cells.

indicate that $\mathrm{AQP} 4$ may play an active role in regulating water and ion concentrations in the CSF. ${ }^{37,86}$

Currently, the majority of existing studies of AQP4 channels and hydrocephalus use experimental animal models. From most studies surveyed, AQP4 channels are found to be upregulated in response to hydrocephalus. However, currently both the specific molecular pathways and the threshold at which upregulation of AQP4 channels occur have not been elucidated.

After inducing acute hydrocephalus in rats with kaolin, Skjolding et al. found that the spatiotemporal distribution of AQP4 channels significantly increases in the days and weeks following induction, suggesting that modifications in AQP4 distribution are part of an important neurodefensive function. ${ }^{119}$ Mao et al. used a kaolin injection model to study rats with severe hydrocephalus over a longer time course. They also observed that AQP4 mRNA was significantly upregulated in the parietal cerebrum and hippocampus within 4 weeks after induction of hydrocephalus, but noted that channel expression does not increase significantly until rats become 7 weeks old (but then stays elevated at the 9-month marker). ${ }^{37,81}$ This indicates that a possible "time-sensitive and pressure or ECF-fluid-adaptive" mechanism may exist due to transparenchymal flow of CSF in hydrocephalus. ${ }^{37,81}$

Following induction of hydrocephalus in rats by $\mathrm{L}-\alpha-$ lysophosphatidylcholine stearoyl injection, Tourdias et al. detected upregulation of periventricular AQP4 in hydrocephalic rats that was strongly correlated with both CSF volume and periventricular apparent diffusion coefficient. Specifically, AQP4 was first mainly located on astrocyte end-feet, but was later distributed over the whole membrane of astrocytes. ${ }^{130}$ These results also suggest that upregulated AQP4 expression is a physiological adaptation to induced hydrocephalus, possibly to aid and facilitate removal of excess water.

In rats with congenital hydrocephalus, Paul et al. found increased expression of AQP4 at the brain-CSF interfaces as well as surrounding astrocyte end-feet and subpial layers in hydrocephalic animals, which also suggests similar compensatory mechanisms to regulate choroidal CSF secretion and parenchymal fluid absorption. ${ }^{100}$ However, AQP4 concentration may not always directly relate to severity of ventricle enlargement in rats with congenital hydrocephalus, as demonstrated by Shen et al. They observed that AQP4 was highly expressed even if rats did not display gross ventriculomegaly (suggesting either a compensatory pathway development or secondary modification in CSF circulation). ${ }^{116}$

Feng et al. experimented with Aqp4-knockout mice, which produced a sporadic $9.6 \%$ rate of encephalomegaly (triventricular hydrocephalus with elevated intracranial pressure [ICP]) by the age of 6 weeks, linking AQP4 to the development of congenital hydrocephalus in mice. ${ }^{34}$ Bloch et al. found accelerated progression of kaolin-induced hydrocephalus in Aqp4-knockout mice when compared with controls, with a significantly higher lateral ventricle volume and ICP measurements as early as 3 days after 
injection, suggesting that the lack of AQP4 channels is related to the development of hydrocephalus. ${ }^{14}$ AQP4 has also been shown to be upregulated after ischemia, but in Aqp4-knockout mice, there is reduced edema formation seen following focal cerebral ischemia, which also suggests a role of AQP4 channels in other aspects of brain water homeostasis. ${ }^{11}$

Hydrocephalus is a disorder characterized by ventricular enlargement, which could arise from different etiologies (congenital or secondary forms) caused by distinct mechanisms at the molecular level. The role of AQP4 may differ depending on the type of hydrocephalus. Excess ventricular fluid accumulation may be caused by CSF overproduction, impaired reabsorption due to obstruction or inflammation, or a combination of both mechanisms. In Aqp1-knockout, Aqp4-knockout, and wild-type mice, Igarashi et al. found that following intravenous injection of $\mathrm{H}_{2}{ }^{17} \mathrm{O}$, water entry into the brain is conducted through AQP4 channels, not AQP1, and that the major site of brain water entry may be the Virchow-Robins space. ${ }^{56}$ In certain types of hydrocephalus, AQP4 channels may be involved in the overproduction of CSF. In these forms of hydrocephalus where overproduction of CSF is implicated, inhibition of AQP4 may be therapeutically desired. It is important to understand the molecular mechanism of hydrocephalus to best design therapies to facilitate the clearance of fluid.

Clearly, numerous studies have elucidated that a link exists between AQP4 channels, brain water balance, and hydrocephalus. The CSF cycle commences at AQP channels in the choroid (i.e., AQP1) and may have a terminus at the BBB interface linking capillary fluid exchange to interstitial fluid through AQP4 channels. ${ }^{95,96}$ This CSF route may also be active in the developing fetal brain, in which the arachnoid villi are not yet developed. ${ }^{44}$ Iliff et al. proposed that CSF cycles through the brain interstitial space, traveling across perivascular spaces and effectively functioning as a sink for brain extracellular solutes, which are removed from cells via AQP4 channels. ${ }^{57}$ According to their hypothesis, AQP4 channels can clear water and solutes from CSF and brain parenchyma. In Aqp4-knockout mice, bulk flow-dependent clearance of interstitial solutes decreased by approximately $70 \% .{ }^{57}$ Iliff et al. posited that the role of AQP4-dependent solute clearance serves as a glial-vascular pathway, which they described as the "glymphatic system." ${ }^{57}$ Quantifying water fluxes across AQP4 channels in the glymphatic pathway (and thus in brain water balance) would be central to exploring the potential of AQP4 channel modulation as a critical step toward molecular treatment options for hydrocephalus. Increasing AQP channels to facilitate CSF clearance to venous drainage, or decreasing AQP channels in areas of CSF production, may both be reasonable strategies for helping to restore and normalize ventricular volumes in patients with hydrocephalus.

\section{Aquaporin-4 Isoforms, Orthogonal Arrays, and Water Permeability}

AQP4 has 3 known isoforms in rats (M1, M23, and $\mathrm{Mz}$ ), and 2 isoforms in human beings (M1 and M23). ${ }^{26,112}$ Following stimulus, astrocytes can alter the ratio of dif- ferent AQP4 isoforms through alternative promoter use to regulate membrane water permeability. ${ }^{103}$ The Aqp 4 gene encodes for 2 different mRNAs with different translationinitiating methionines (M1 or M23); however, both isoforms are expressed in AQP4-expressing tissue. ${ }^{136}$ The existence of multiple AQP4 isoforms has been associated with distinct translational efficiencies, organ-specific expression, developmental regulation, formation of square arrays on cellular membranes, and different water conduction rates. ${ }^{5,25,35,39,137,141}$ In rats, 6 cDNA isoforms resulting from alternative splicing have been discovered, and 3 protein isoforms (M1, M23, and Mz) were identified. ${ }^{87,112}$ In the brain, the ratio of M23 to M1 isoforms is 7:1, and the quantity of $\mathrm{Mz}$ isoform is very scarce. ${ }^{90} \mathrm{The} \mathrm{Mz}$ isoform is absent in human tissues due to the presence of a stop codon.

AQP4 channels exist in the endoplasmic reticulum and Golgi membranes as tetramers, but are seen in large square arrays in the plasma membrane. ${ }^{111}$ AQP4-channel tetramers assemble into higher-order aggregates termed orthogonal arrays (or square arrays) through the interaction of critical residues on adjacent tetramers. ${ }^{39}$ The formation of AQP4 oligomers on the plasma membrane is a membrane curvature-dependent process that involves yet unknown factors on the plasma membrane. Most likely, the assembly of AQP4 into oligomers occurs prior to expression on the plasma membrane, but not in the endoplasmic reticulum or the Golgi membrane. Given that the size of transport vesicles for proteins traveling through the secretary pathway generally falls between 40 and 70 $\mathrm{nm},{ }^{132} \mathrm{AQP} 4$ channels are probably transported in vesicles as tetramers. ${ }^{11}$

Square arrays are approximately $30-150 \mathrm{~nm}$ in size, as observed in electron micrographs of astroglial endfoot membranes. ${ }^{107}$ The 3 isoforms differ in their ability to form orthogonal arrays on cellular membranes. The M23 isoform forms large square arrays, the M1 isoform forms small or unstable square arrays, and the Mz isoform does not form arrays. ${ }^{39,107,112}$ The expression of M23 and M1 isoforms in different ratios can control square array size ${ }^{39}$ The interference of M23-M23 interaction by a residue at the N-terminus of $\mathrm{M} 1$ prevents the formation of stable arrays between M1-M23 or M1-M1 interactions. ${ }^{124}$ The functions of these orthogonal arrays are currently an active area of research. The size of square arrays influences the water conductivity of AQP4 channels. The single-channel water permeability of M23 is approximately 8 times greater than that of M1, likely due to the ability of M23 to form stable square arrays. ${ }^{118}$ It has been further suggested that the larger the array, the more it is able to accommodate a higher water flux through the membrane induced by an osmotic gradient, consistent with the speculation that AQP4 could play an adhesive role at gap junctions. 48

At the end-foot cellular membrane near the perivascular space, the anchoring of AQP4 requires $\alpha$-syntrophin, a member of the dystrophin complex. Syntrophin-null mice show normal overall levels of AQP4 in the brain, but have a 90\% reduction in AQP4 immunolabeling in the end-feet near the perivascular space., ${ }^{7,89}$ However, only a $50 \%$ reduction is observed in end-feet opposing the pial mem- 
brane. ${ }^{7}$ It is possible that molecules other than $\alpha$-syntrophin are required to maintain the polarization and anchoring of AQP4 near the end-foot membrane opposing pia. The difference in anchoring mechanisms of the different cellular AQP4 pools may indicate a differential regulation of AQP4 membrane expression during neurological injury, where AQP4 anchoring in certain end-feet structures may be preserved while in others it is disrupted to control the region-specific dynamics of water clearance.

Because AQP4 anchoring in different domains of the astrocyte membrane is achieved by different molecular complexes, the spatially heterogeneous expression patterns of AQP4 in the postinjury brain (such as end-feet around the BBB versus pial end-feet) are likely achieved through differential regulation of these membrane pools through distinct signaling pathways. ' Loss of AQP4 at the end-feet opposing the BBB has been found after ischemia, also supporting the idea of cell region-specific anchoring mechanisms. ${ }^{68}$ However, this role of AQP4 array in intercellular adhesion is generally debated. ${ }^{38,143}$

\section{Alternative Promoters and Transcription Factors}

The use of alternative promoters of the Aqp 4 gene and the differential activation of these promoters during pathological processes may have implications in the regulation of brain water permeability in disease processes, including hydrocephalus. As previously mentioned, numerous studies have shown upregulation of AQP4 expression in hydrocephalic states. Regulatory mechanisms of AQP4 and its role in neurological diseases were recently reviewed by Hsu et al. ${ }^{53}$ Transcription factors capable of activating the Aqp4 gene may play an important role in the regulation of AQP4 expression in neurological disorders; in oxidative stress, it has been elucidated that gene nuclear factor (erythroid-derived 2)-like 2 (Nrf2) activates AQP4. ${ }^{131,144}$ Umenishi and Verkman studied the promoter regions associated with exon 0 and exon 1 of the human Aqp 4 gene, and found that the M1 isoform is encoded starting from exon 0 , and the M23 isoform from exon $1 .{ }^{131}$ Exon 1 has stronger transcriptional activity than exon 0 . However, promoter activity of exon 0 has stronger relative activity in brain-derived cells than kidney-derived cells, indicating an organ-specific regulation.

For the M1 isoform, the exon 0 promoter contains 4 TATA boxes, 5 CCAAT boxes, activating protein-1 (AP1), Sp1, and E-box elements. ${ }^{131}$ AP-1 is the primary target of the p38 mitogen-activated protein kinase signaling pathway, which has been confirmed to upregulate AQP4.97 On the other hand, E-box is known to have strong inhibition activities on Aqp 4 transcription. ${ }^{131}$ In the mouse Aqp4 gene, an astrocyte-specific enhancer has been identified upstream of exon $0 .^{1}$ This enhancer is associated with the Pit-1/Oct/Unc-86 transcription factor family, and is probably responsible for the high expression of AQP4 in brain astrocytes compared with other cell types. However, the roles of the rest of the binding sites in the promoter are unknown. CCAAT-enhancer binding proteins belong to the acute response genes, however, and their effect on AQP4 expression is not known.
For the M23 isoform, the exon 1 promoter contains 1 TATA box, AP-1, AP-2, and E-box elements. ${ }^{131}$ A possible binding site for NF- $\mathrm{KB}$ transcription factor in exon 1 promoter construct has been found, and interleukin-1-induced NF- $\kappa \mathrm{B}$ activation has been confirmed to upregulate $\mathrm{AQP} 4 .{ }^{59} \mathrm{AP}-2$ is a developmentally regulated transcription factor that participates in embryogenesis, and may be a potential regulator of AQP4 in the developing brain. ${ }^{138}$ The expression of both M1 and M23 AQP4 isoforms increased in the postnatal periods of rats. ${ }^{137}$ Moreover, AQP4 expression in the hippocampus increases gradually from P9 through 3 weeks and 6 weeks in a laminar-specific pattern. ${ }^{52}$ The possible role of AP-2 in AQP4 developmental regulation remains to be elucidated.

\section{Posttranslational Modification}

Astrocytes regulate their membrane water permeability through AQP4 channels by employing transcriptional, translational, and posttranslational control mechanisms. Neurological disease processes such as hydrocephalus may involve the dysregulation of AQP4 signaling pathways - a product of a combination of transcriptional events and pathways, as depicted in a signaling map by Hsu et al. ${ }^{53}$ After the translation process, phosphorylation of several amino acid residues on the polypeptide chain is required for the correct trafficking, expression, and membrane targeting of AQP4, as well as for its assembly into higher-order arrays. The phosphorylation of AQP4 can effectively and rapidly change membrane water permeability through either endocytosis of the water channels or the disruption of square array formation. In terms of pharmacological interventions, targeting AQP4 posttranslational mechanisms, such as phosphorylation, will probably result in a rapid and transient effect compared with transcriptional or translational regulation strategies. Here, we briefly summarize posttranslational modification of the AQP4 polypeptide and its effect on the function and subcellular localization of AQP4.

Immediately after the emergence of the polypeptide from the ribosomes, the translocon Sec61 $\alpha$ inserts the 6 membrane domains sequentially into the endoplasmic reticulum membrane. ${ }^{113}$ After the translation event, the transition through the Golgi apparatus requires the phosphorylation of AQP4 by casein kinase-2 (CK-2) at several amino acid residues in the C-terminal domain. AQP4 is constitutively phosphorylated, and a quadruple-substitution mutant of M1 AQP4 at $\mathrm{Ser}^{276}, \mathrm{Ser}^{285}, \mathrm{Thr}^{289}$, and $\mathrm{Ser}^{316}$, which prevents its phosphorylation by CK-2, accumulates inside the Golgi apparatus. This evidence strongly suggests that the phosphorylation of these residues is required for the Golgi transition of AQP4 ${ }^{61}$ Leaving the Golgi apparatus, AQP4 proteins localize to the cell membrane. Confirmed AQP4 phosphorylation sites and their effects on AQP4 trafficking are shown in Fig. 3, built upon an AQP polypeptide adapted from Ratelade and Verkman. ${ }^{108}$

The phosphorylation of AQP4 at different amino acid residues can alter the single-channel water permeability (as shown in the left column of Fig. 3). Gunnarson et al. found that water permeability is increased through the phosphorylation of $\mathrm{Ser}^{111}$ by the activation of group I glu- 


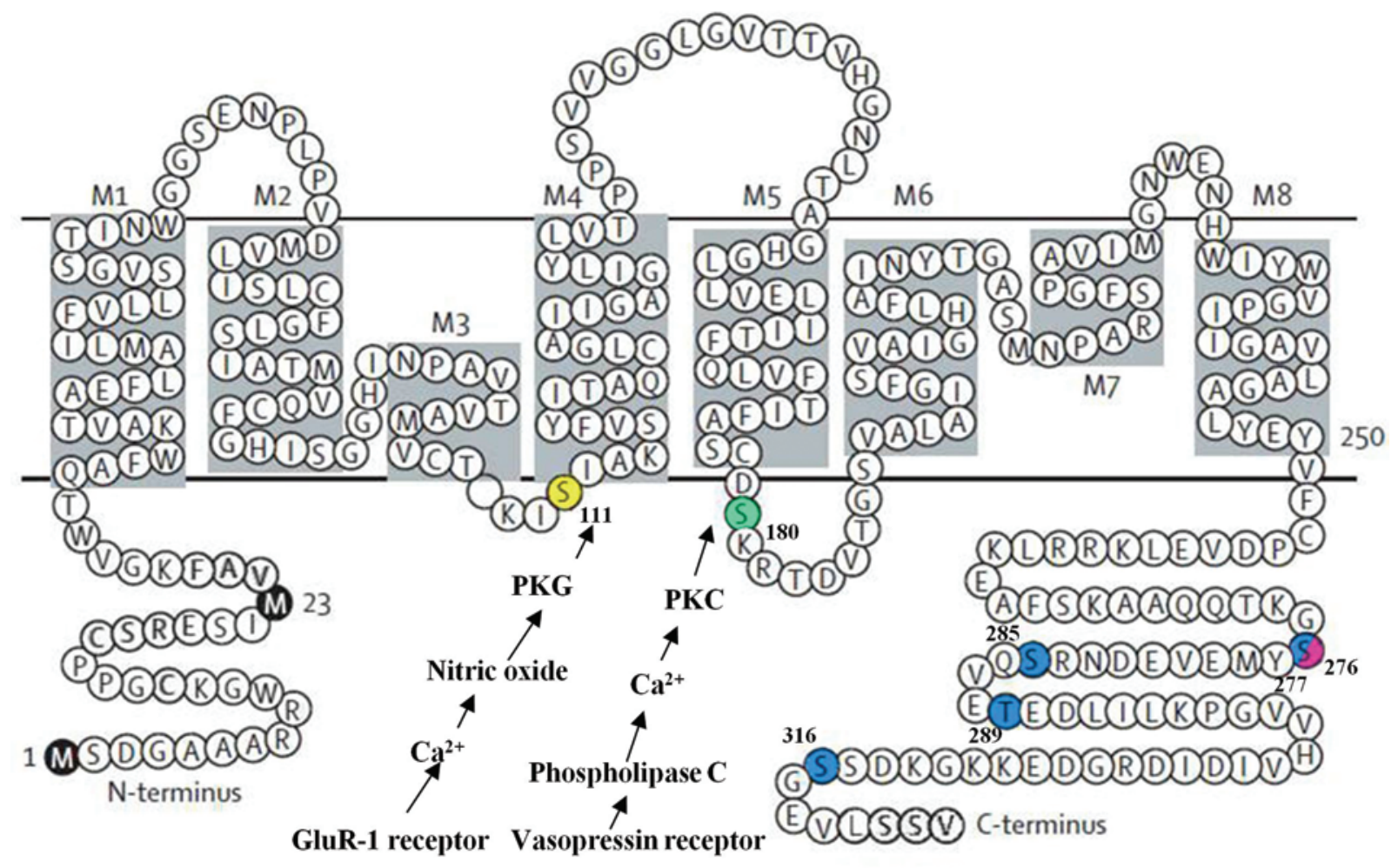

Permeability of water pore

Phosphorylation of Ser111 by glutamate plays a disputed role in increasing water permeability (signaling shown)

Phosphorylation of Ser 180 by a PKC activator also decreases permeability through internalization-independent mechanism in mammalian cells

\section{Trafficking and subcellular localization}

Phosphorylation of Ser 180 by a PKC activator increases AQP4 internalization in oocytes (signaling shown)

Phosphorylation of Ser276, 285, 289, 316 by CK-2 is necessary for Golgi transition

Phosphorylation of Ser276 is required for the targeting and mobilization of endosomal AQP4

Interaction of Tyrosine 277 with adaptor protein2 is required for endocytosis

FIG. 3. Confirmed AQP4 phosphorylation sites and their effects on AQP4, as depicted on an AQP polypeptide. Structure adapted from Ratelade and Verkman 2012.

tamate receptors (mGluR-I) ${ }^{46}$ The activation of mGluR-I can be induced by endogenous glutamate or by an agonist ${ }^{46}$ mGluR-I stimulation causes the release of $\mathrm{Ca}^{2+}$ from intracellular stores, which leads to nitric oxide production and the activation of protein kinase G (PKG), which phosphorylates Ser ${ }^{111}{ }^{46}$ Silberstein et al. found that a phosphomimetic M23-Ser ${ }^{111 \mathrm{E}}$ forms 2.5-times larger square arrays compared with wild-type M23 and possesses a 1.5-fold increase in single-channel water permeability. ${ }^{118}$

However, Assentoft et al. did not find an increase in water permeability in oocytes transfected with AQP4 with a phosphomimetic Ser ${ }^{11}$ site or in oocytes transfect- ed with AQP4 and treated with protein kinase A (PKA) or PKG activators. ${ }^{9}$ They also did not detect evidence of Ser ${ }^{11}$ phosphorylation in vivo after treating animals with an mGluR1/5 analog. ${ }^{9}$ Their evidence argues against the regulation of AQP4 water permeability via Ser ${ }^{111}$ phosphorylation. Because astrocytic $\mathrm{Ca}^{2+}$ waves are known to propagate through the astrocyte syncytium via interconnected gap junctions, it is possible that $\mathrm{Ca}^{2+}$ signaling is a fast-acting and long-range control mechanism of astrocytic membrane water permeability. Deletion of AQP4 channels has also been found to reduce $\mathrm{Ca}^{2+}$ signaling. ${ }^{28}$

Following AQP4 expression on the cellular membrane, 
posttranslational regulation mechanisms allow a rapid alteration of water permeability. A transient and rapid alteration of cell water permeability can be accomplished by the endocytosis of AQP4 channels expressed on the membrane. AQP4 is endocytosed through interactions of the tyrosine motif at the C-terminus with adaptor protein-2 complex in clathrin-coated pits. ${ }^{80}$ AQP4 endocytosis was reduced by $80 \%$ when either the $\mathrm{Tyr}^{277}$ was replaced with an alanine, or when $\mathrm{Val}^{280}$ was replaced with a serine. The tyrosine motif YMEV at the AQP4 C-terminus directly interacts with the adaptor protein-2 clathrin-adaptor complex to mediate endocytosis. A majority of the endocytosed AQP4 is directed to the lysosomes for degradation, and this lysosomal targeting of AQP4 is increased when $\mathrm{Ser}^{276}$ is phosphorylated by CK- $2 .{ }^{80}$

A recent study showed that hypotonicity induces a rapid membrane localization of AQP4 through a PKA-calmodulin signaling mechanism, which involves the $\mathrm{Ser}^{276}$ phosphorylation site. ${ }^{66}$ Interestingly, Ser ${ }^{276}$ phosphomimetic mutation is not sufficient to increase AQP4 membrane translocation, but the mutation of $\operatorname{Ser}^{276}$ to alanine blocks hypotonicity-induced translocation, indicating that $\operatorname{Ser}^{276}$ phosphorylation is necessary but not sufficient for AQP4 membrane translocation. ${ }^{66}$ Together with the report that $\mathrm{Ser}^{276}$ phosphorylation increases AQP4 targeting to lysosomes, this evidence could suggest that the phosphorylation of $\mathrm{Ser}^{276}$ on AQP4 is a necessary signal for initiating subcellular targeting of the endosomal pool of AQP4, but the specific subcellular destination of the endosomal AQP4 relies on additional modification signals.

The internalization of AQP4 expressed in Xenopus oocytes can be initiated by protein kinase $\mathrm{C}$ (PKC) activation, which is at least partially mediated by the phosphorylation of $\mathrm{Ser}^{180}{ }^{88}$ In PKC-induced internalization, AQP4 remains intact inside its cytosolic compartments without degradation, which can allow the reexpression of AQP4 on the membrane ${ }^{88}$ The phosphorylation of $\mathrm{Ser}^{180}$ by PKC activators, including dopamine, has been reported to decrease the water pore permeability without the internalization of AQP4 in pig kidney epithelial cells as opposed to findings by Moeller et al. and Zelenina et al ${ }^{88,142}$ These 2 studies show that the posttranslational regulation of cell membrane versus internal AQP4 pools are controlled by different mechanisms in mammalian versus oocyte cells. AQP4 upregulation after ischemia is also reversed by PKC activation at the transcriptional level, showing that PKC signaling reduces AQP4-mediated water permeability through both transcriptional and posttranslational mechanisms ${ }^{68}$ Reversible internalization of membrane AQP4 has also been shown to be triggered by histamine exposure. ${ }^{20}$

\section{Aquaporin-4 Channels: A Potential Therapeutic Drug Target for Hydrocephalus?}

Current treatment strategies for hydrocephalus involve mechanical shunting of excess CSF. Surgery and mechanical strategies are effective, but are not without complications. A study of 14,455 individuals revealed a 5-year complication rate of $32 \%$ for ventriculoperitoneal shunts, and another study of 1015 individuals founds an overall failure rate (requiring shunt revision) of $46.3 \%{ }^{109,139}$ Del Bigio and
Di Curzio recently published a comprehensive review of current nonsurgical therapeutic options for hydrocephalus, reviewing efficacy of osmotic agents, acetazolamide, ion channel blockers, steroids, and other agents; they concluded that no compelling nonsurgical therapies have yet been developed for hydrocephalus. ${ }^{28}$ Regarding osmotic agents, Del Bigio concludes that although mannitol is used widely in treatment of an acute "elevated ICP in situations of brain swelling," it is seldom used in hydrocephalus. ${ }^{28}$ Some studies have shown that mannitol/urea, which induces hyperosmolarity in the blood and induces water flux from brain to blood, may cause a rebound elevation in ICP when given to children with hydrocephus. ${ }^{28,31,47}$

The administration of osmotic agents alone has not been found to be useful. However, in the future, treatments aimed at interfering with CSF production may create noninvasive management options for some types of hydrocephalus. A review by Poca and Sahuquillo concluded that the most suitable current drug therapy for hydrocephalus appears to be acetazolamide (with or without furosemide). These authors also stated that osmotic agents are no longer considered efficacious in the treatment of hydrocephalus. ${ }^{104}$ In 1980, Smith and Johanson showed that carbonic anhydrase inhibitors (acetazolamide and benzolamide) interfered with ion transport, decreasing basolateral sodium entry into the choroid epithelium and decreasing the rate of the apical sodium/potassium pump. ${ }^{120}$ Acetazolamide has also been shown to inhibit AQP-mediated water conductance in relation to inhibition of choroid plexus carbonic anhydrase. ${ }^{125}$ In human subjects, acetazolamide treatment has mixed reviews, with some authors noting therapeutic benefit in different case studies over the years; recent studies state that some patients are "responders" to acetazolamide therapy whereas others are "nonresponders." $83,85,102,123$

Gao et al. have described beneficial aspects of acetazolamide treatment, i.e., marked attenuation of thrombin-induced hydrocephalus in rats (intraventricular hemorrhage model); this also suggests a decreased CSF production mechanism. ${ }^{41,42}$ Poca and Sahuquillo mentioned efficacy with the injection of fibrinolytic therapy directly into the ventricular system to similarly aid posthemorrhagic hydrocephalus management by reducing postshunt complications, such as catheter obstruction. ${ }^{104}$ In fact, several recent studies have found that intraventricular tissue plasminogen activator is a safe and effective method for improving CSF shunting, with low risk of bleeding, infection, and other adverse effects; intraventricular tissue plasminogen activator may aid an acute treatment strategy, but by itself it is not a long-term treatment method for hydrocephalus. ${ }^{30,106,146}$

Currently, existing studies of water channels and hydrocephalus confirm that AQP4 channels are generally upregulated in response to congenital hydrocephalus. ${ }^{21}$ Either facilitating water clearance via AQP4 upregulation or reducing CSF production via $\mathrm{AQP1}$ downregulation are both plausible mechanisms of action to help treat hydrocephalus. ${ }^{95,96}$ AQP channels are directly involved in bulk water movement in the brain, including CSF production and elimination. ${ }^{126,133,134,140}$ Water diffusion has been found to be altered in the brain via Aqp gene deletion, RNAi, lead exposure, and numerous other methods..$^{10,45,53,91,121} \mathrm{By}$ 
using diffusion-weighted imaging to measure changes in water diffusion, Badaut et al. found that RNAi knockdown of AQP4 led to a $50 \%$ reduction in water mobility. ${ }^{10}$ As a therapeutic target, targeting AQP4 posttranslational mechanisms such as phosphorylation will probably result in rapid and transient changes in AQP expression compared with transcriptional or translational regulation strategies.

Current research on AQP4 channel modulation has shown that a variety of different compounds inhibit AQP4 channels. Via in vitro functional assays, arylsulfonamide drugs (antiepileptic agents) have been shown to function as AQP4 inhibitors. ${ }^{54,55}$ Similarly, gold and silver compounds have also been shown to function as AQP inhibitors. ${ }^{93} \mathrm{Mi}-$ gliati et al. found that bumetanide and functional derivatives reduce AQP4 osmotic water flux in AQP4-expressing Xenopus laevis oocytes. ${ }^{84}$ Kato et al. found that the general anesthetic propofol (2,6-diisopropylphenol) reversibly and specifically inhibits the osmotic water permeability of AQP4 proteoliposomes in the presence of $\mathrm{Zn}^{2+}{ }^{23} \mathrm{De} \mathrm{Bel}-$ lis et al. found that transfection of a human Aqp4 splice variant exhibits a dominant-negative activity, decreasing AQP4 expression. ${ }^{26}$

Ambarki et al. found that piroxicam pretreatment in ischemia-reperfusion injury is neuroprotective, with significantly reduced brain edema linked to a downregulation of AQP4 channel expression. ${ }^{6}$ An interesting evaluation would be to note whether the piroxicam effects on focal cerebral ischemia also translate to therapeutic benefit in AQP4 modulation as a treatment for hydrocephalus. Papadopoulos and Verkman highlighted potential benefits of AQP modulation in a variety of brain diseases; they noted that small-molecule AQP4 inhibitor development progress has been slow, stemming from technical issues and "poor druggability" of the AQP channel..$^{98,135}$ They also described AQP4 inhibitors as 4 classes of AQP-targeted small molecules: "cysteine-reactive heavy metal-based inhibitors; small-molecule scaffolds that are reported to inhibit water conductance; small molecules that target the interaction between AQP4 and the NMO autoantibody; and agents that act as chemical chaperones to facilitate the cellular processing of NDI-causing AQP2 mutants." 135

In terms of enhancing AQP4 channel function, there are many fewer researched methods. Aqp gene transfer is a promising concept, which has been shown to be efficacious in rats, pigs, and finally a small group of patients who were treated with adenoviral-mediated transfer of the $A q p-1$ cDNA as a treatment for radiation-induced salivary hypofunction..$^{12,13,43}$ Similar Aqp gene transfer may be adapted as a treatment for hydrocephalus, by increasing the number of AQP4 channels to help mediate water balance in the ventricular system. Although not clear if applicable to the ventricular AQP4, studies have shown increased AQP4 expression secondary to nitric oxide and lipopolysaccharide in neural tissue. ${ }^{72,94}$

Based on the experiments conducted regarding AQP4 expression, it is possible to conclude that upregulating AQP4 channels may improve water clearance in hydrocephalus. However, it is still relatively unknown what molecular mechanisms drive AQP4 modifications in the brain in hydrocephalus. A recent study by Aghayev et al. discovered that in rats, AQP4 expression is not increased in mild hydrocephalus (during initial stages), but it is increased in severe hydrocephalus. ${ }^{2}$ If these observations carry over to human beings, this may decrease the efficacy of potential therapeutic AQP4 modulators in early hydrocephalus.

The upregulation of AQP4 near the ventricles in severe hydrocephalus may also be a result of the inflammatory markers implicated in the pathogenesis of hydrocephalus (including tumor necrosis factor- $\alpha$, interleukin- $1 \beta$, and transforming growth factor- $\beta$ ), and not purely a protective mechanism to improve water clearance. ${ }^{19,73,127}$ In addition to the water and ion homeostatic functions of AQP4, it has been suggested that AQP4 functions as a cell adhesion molecule, plays a role in the structural and functional integrity of the ependyma, and modulates size regulation of orthogonal arrays; these factors should be kept in mind when designing targeted therapies for AQP4. ${ }^{33,48,75,119}$

AQP4 channels have also been found to play a role in regulating adult neurogenesis and stem cell proliferation. ${ }^{69,119,145}$ Another concern related to regulating AQP4 for pharmaceutical uses is that it may have a variety of effects on the body; AQP4 channels are not only located in the CNS, but also in skeletal muscle sarcolemma, the male genital system (seminiferous tubules, seminal vesicles, prostate, and epididymis), the respiratory system (lung and bronchus), the kidney, the gastrointestinal system (parietal cells and salivary glands), and in various other parts of the human body. 86

However, these challenges are not insurmountable. Many other currently used systemic therapies with a specific target may have numerous systemic effects (e.g., antihistamines, NSAIDs, and so on). Beneficial AQP4 modulators must have minimal neurotoxicity and beneficial pharmacological parameters, and also be able to cross the BBB and be effective medications. If the benefits of therapy are able to overcome side effects, pharmacological agents targeting AQPs may pose a viable route to help treat hydrocephalus, either in conjunction with current surgical methods or as a monotherapy when surgery is contraindicated (Table 1).

\section{Computational Modeling of CSF Transport}

The discussion of AQP4 channels and the role of intracranial water shift in hydrocephalus clearly underscores the importance of molecular transport processes for normal homeostasis of brain water and in the disease process of hydrocephalus. Quantifying the impact of AQP channels on brain fluid exchange would help researchers to elucidate the causes of hydrocephalus, its progression, and how to treat it. A quantitative understanding of the production and flow of CSF is vital to gaining more accurate insight into the pathological changes that occur in hydrocephalus. Physiological CSF flow, possibly mediated by the amount and placement of AQP channels, is an important aspect of the ventricular system-from the initial ependymal-cell CSF production in the choroid plexus, surface of the ventricles, and lining of the subarachnoid space, to the eventual travel of the fluid through the third and fourth ventricles, and finally to the subarachnoid space and reabsorption to the vascular system. Physiologically accurate computational modeling of fluid flow in hydrocephalus will help to design bypass strategies in noncommunicat- 
TABLE 1. Key points by subtopic

\begin{tabular}{cc}
\hline \multicolumn{1}{c}{ Subtopic } & \multicolumn{1}{c}{ Key Points } \\
\hline $\begin{array}{c}\text { AQP4 \& hydro- } \\
\text { cephalus }\end{array}$ & $\begin{array}{c}\text { AQP4 channels are intimately involved in brain } \\
\text { water regulation. Numerous studies have } \\
\text { shown a link btwn hydrocephalus \& second- } \\
\text { ary changes in AQP4 expression, as well as } \\
\text { primary Aqp4 knockout leading to accelerated } \\
\text { development of hydrocephalus. }\end{array}$ \\
\hline $\begin{array}{c}\text { AQP4 channel } \\
\text { characteristics }\end{array}$ & $\begin{array}{c}\text { A review has been performed of elucidated } \\
\text { AQP4 isoforms, orthogonal arrays, alternative } \\
\text { promotors, transcription factors, \& post- } \\
\text { translational modification. Further molecular } \\
\text { research on AQP4 channels will supplement } \\
\text { the development of drug therapy. }\end{array}$ \\
\hline $\begin{array}{c}\text { Eqfective pharmaceutical methods for treatment } \\
\text { of hydrocephalus do not exist. AQP4 is an at- } \\
\text { therapeutic } \\
\text { cephalus? }\end{array}$ & $\begin{array}{l}\text { tractive target for drug therapy. Compounds to } \\
\text { modulate AQP4 function are under develop- } \\
\text { ment \& face potential limitations. }\end{array}$ \\
\hline $\begin{array}{c}\text { Computational } \\
\text { modeling of CSF } \\
\text { transport }\end{array}$ & $\begin{array}{l}\text { Three aspects of computational modeling of } \\
\text { hydrocephalus deserve further attention: ICP, } \\
\text { ventricular vol, \& osmolarity. Accurate com- } \\
\text { putational models of the ventricular system } \\
\text { developed from real-time imaging may help } \\
\text { improve early diagnosis as well as surgical } \\
\text { planning for hydrocephalus. }\end{array}$ \\
\hline &
\end{tabular}

ing hydrocephalus, as well as complement shunting device placement, and will also help to design how to best restore normal CSF exchange in communicating hydrocephalus. ${ }^{77}$ Many groups have proposed computer models to describe CSF flow dynamics in the ventricular system, showing that it is possible to model the disease process of hydrocephalus. ${ }^{6,17,40,49,50,58,77,78}$

Previous models of hydrocephalus divided the cranial space into individual compartments, such as ventricles, parenchyma, cerebral blood, and cranial subarachnoidal space. Externally imposed changes to fluid exchange between these compartments, such as obstruction of the villi, induce accumulation of the fluid and subsequently lead to CSF accumulation in the ventricular system. $.^{16,18,78} \mathrm{Com}-$ partmental models often incorporate compliance curves that link cranial compartment volume with the $\mathrm{ICP}^{78}$ However, when incorporating intracranial compliance curves, the relationships between pressure and volume are given as inputs, and thus are not predictive. As such, compartmental models based on predefined fluid exchange and cerebral compliance laws merely reproduce known effects, such as enlargement of ventricles and pressure changes, without actually addressing the biochemical changes that occur at the molecular level.

Therefore, simplified compartmental models lacking molecular water-transport aspects can reproduce changes that occur in hydrocephalus (such as ventricular enlargement and pressure changes), but have so far not been successful in improving diagnosis or treatment options. To improve diagnosis of hydrocephalus and its management, a new family of models is needed that addresses the pathology at the molecular level in addition to the macroscopic changes that are observed clinically. Based on the review of molecular aspects of water transport in the brain, 3 significant aspects appear to deserve more attention in future computational models of hydrocephalus and diseases that involve CSF dynamics. These include ICP, ventricular volume, and osmolarity.

The first subject in need of further clarification is ICP. For physicians, ICP is a well-recognized clinical quantity that can be measured with spinal tap or monitored acutely with pressure sensors. ${ }^{36,74,114}$ In computational models of intracranial dynamics, pressure differences are calculated using the equations of motion for the CSF, the NavierStokes equations. A recent review by Linninger et al. summarized models of CSF dynamics and diseases. ${ }^{77}$ Most existing computational models use an incompressible fluid assumption that does not set a specific value for absolute hydrostatic pressure (ICP). Thus incompressibility merely implies a "pressure drop" needed to entertain fluid motion by overcoming viscous frictional losses, but it does not correlate to absolute ICP.

What is needed are more complete molecular or biochemical models to accurately quantify absolute pressure changes caused by tissue deformations such as ventricular enlargement; compression of the cerebral arterial, capillary, and venous blood pools; or expansions of the spinal subarachnoid space. Such models require fluid-structure interaction between CSF and brain matter, while simultaneously incorporating blood flow and CSF interactions..$^{22}$ More fundamental models addressing compressibility and deformations between fluid and solid compartments will create true predictions of ICP rise subject to external influences, by correlating physical and molecular aspects of intracranial water exchanges and CSF dynamics. These predictions will provide relevant information, so that ICP changes in the CSF and its effects on cerebral blood flow and brain tissue can be explained.

A second question concerns the impact of ICP and compressibility on volume changes of intracranial compartments. It is not clear how ICP rise leads specifically to an increase in the size of the ventricles, rather than modifications in other spaces in the CSF system such as the subarachnoid space. In Hakim's original "water-filled sponge" hypothesis of the brain (see article by Clarke and Meyer), ICP rise was seen to induce a mechanical wall deformation leading to the enlargements of the ventricles. ${ }^{23}$ However, work by Linninger et al. and Penn et al. showed that ICP differences are small, and it is unlikely that mechanical deformation alone causes ventricular enlargement in hydrocephalus. ${ }^{76,101}$

Uncertainty also pertains to the exact location of spatial displacement needed to accommodate ventricular enlargement. It is well known that ventriculomegaly is a symptom of hydrocephalus. However, it is poorly understood which spaces are displaced when ventricles enlarge. One option is that the extracellular space in the parenchyma diminishes. Work by Del Bigio and colleagues supports the finding that the extracellular volume fraction is smaller in hydrocephalic animals when compared with normal specimens. ${ }^{27,29,117}$ However, the experimental techniques to measure minimal changes rely on tissue fixation, which is prone to altering the extracellular space. Therefore, it is 
not clear whether the extracellular space volume fraction truly shrinks after ventricular enlargement. It would be invaluable to further investigate possible alterations of extracellular space in hydrocephalus, for example, by using specialized integrated optical imaging methods developed by Nicholson ${ }^{62}$ or by diffusion-tensor imaging methods. ${ }^{62,115}$

Another theory regarding hydrocephalic CSF accumulation in the ventricles is that volume compensation occurs by expansion of the cortical surfaces, thus reducing the cranial subarachnoid space available to the CSF. Accordingly, the CSF volume that is needed to enlarge ventricles would merely shift from the cranial subarachnoid space to the ventricles. This process could take effect without the need for actual CSF accumulation or changes to CSF production or reabsorption. Figure 4 illustrates the space relationships. Figure 4A, C, and E shows a normal human cortex generated from medical images. The model shown by Fig. 4B, D, and F was generated artificially by expanding the cortical surface by $1 \mathrm{~mm}$ from the actual cortical surface (a 1-mm-level set increase in size).

This modest expansion of the cortical surface substantially reduces the CSF volume occupied by the cranial subarachnoidal space. The cortical surface shifts in the hypothetical expansion are close to the image resolution threshold, so it may be difficult to detect these in a patient's MR image. Figure 4 also shows that these changes in the subarachnoid space may easily be dismissed as anatomical variability between patients. Distance maps were created to precisely quantify the volume difference due to a 1-mm cortical expansion. Two different "masks" (shown in Fig. 5) were entered into an algorithm to calculate the volume difference of $185.9 \mathrm{ml}$ between the normal and the expanded cortical surfaces. Thus, the 1-mm shift in cortical surface corresponded to a total of $185.9 \mathrm{ml}$ of CSF volume change.

From a volumetric point of view, this shows that the entirety of a substantial ventricular enlargement could be accommodated by small expansions of the cortical surface. If this were true in hydrocephalus, the expansion of CSF volume may not solely constitute an accumulation of water pressing on neural tissue, but also a redistribution of CSF from the cranial subarachnoid space to ventricular spaces. Whether the expansion of the ventricle causes extracellular space reduction/compression, or redistribution of water volume from the cranial subarachnoid space to the ventricular system, is currently poorly explored. Advances in medical imaging and segmentation algorithms are expected to clarify which final volume shifts occur in hydrocephalus, thus allowing us to calculate ventricular volume changes for patients.

The third area of interest in hydrocephalus pertains to the effect of osmolarity. It has been shown in experiments that the change of CSF osmolarity alone may be sufficient to alter ventricular size. Two groups have shown that artificial change of osmolarity in ventricular CSF by hyperosmolar infusion into the ventricular system is followed by ventricular enlargement. ${ }^{67,70,71}$ If these experiments prove to be valid, it would suggest that ventricular expansion can occur merely by changing the osmolarity, without the specific need for pressure changes or physiological infusion of water.
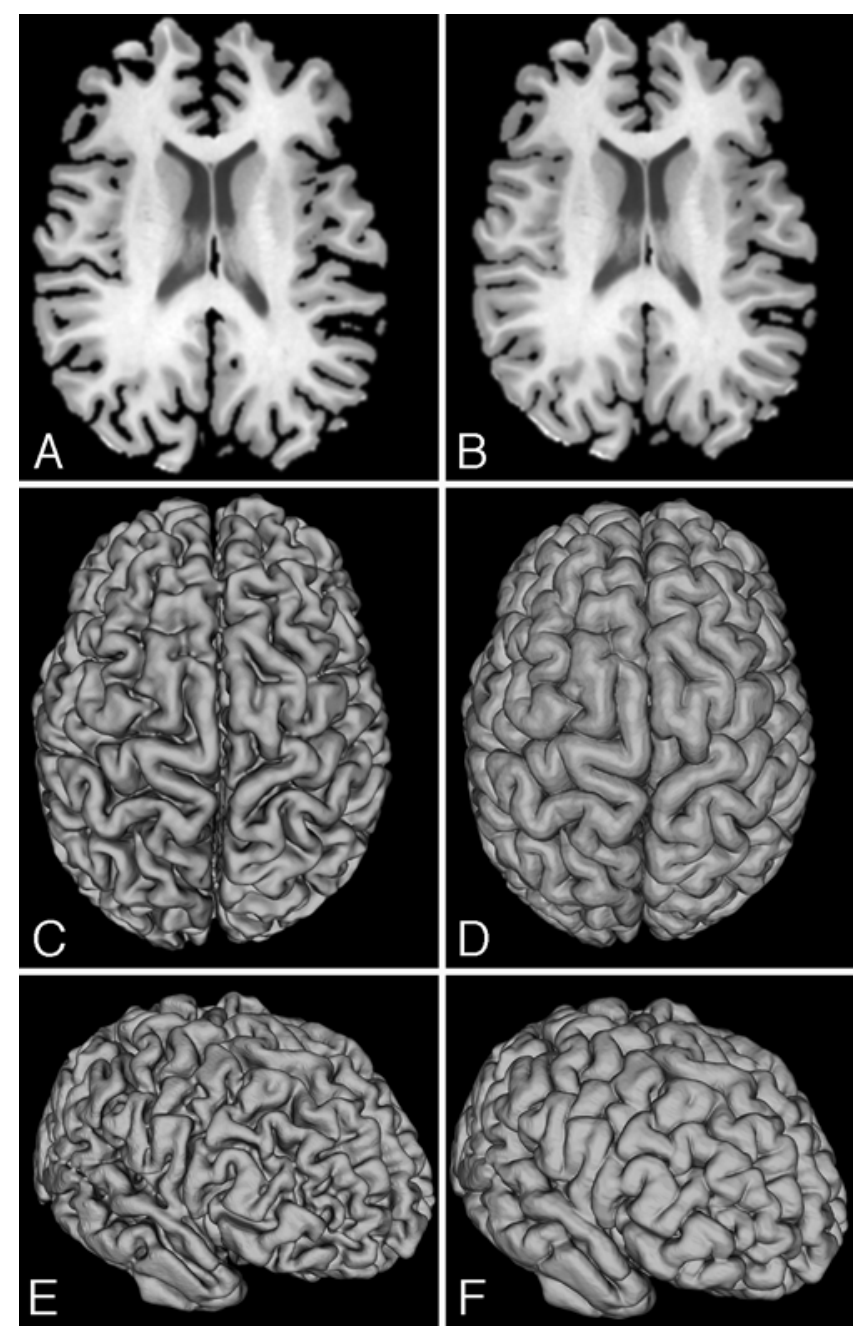

FIG. 4. Volume changes depicted by 3D reconstruction of MR images, following a 1-mm shift of the cortical surface. A and B: A 1-mm shift in the cortical surface is not grossly perceptible on the comparison transverse section. A, C, and E: Cortical surface reconstruction of a volunteer. B, D, and F: Cortical surfaces following a uniform 1-mm shift of the cortical surface.

This evidence suggests that osmolarity changes affect intracranial water shifts via the secondary flux of water through the AQP water channels, which are known to operate by means of osmolar gradients. A transiently hyperosmolar CSF would then be implicated in hydrocephalus, because it is established that the choroid plexus secretion of sodium and chloride may cause the development of hydrocephalus. ${ }^{122}$

This contribution of osmolarity and thus AQP water channels to hydrocephalus should not be ignored in the current understanding of hydrocephalus, and thus needs to be accounted for in computational models of hydrocephalus. Whereas experimental evidence generates new data about hydrocephalus disease progression, computational models currently lag behind in introducing these phenomena into a quantitative biochemical and biomechanical model to explain the molecular aspects of hydrocephalus. A first attempt to quantify osmolarity and fluid exchange in the brain was described recently. ${ }^{17}$ 


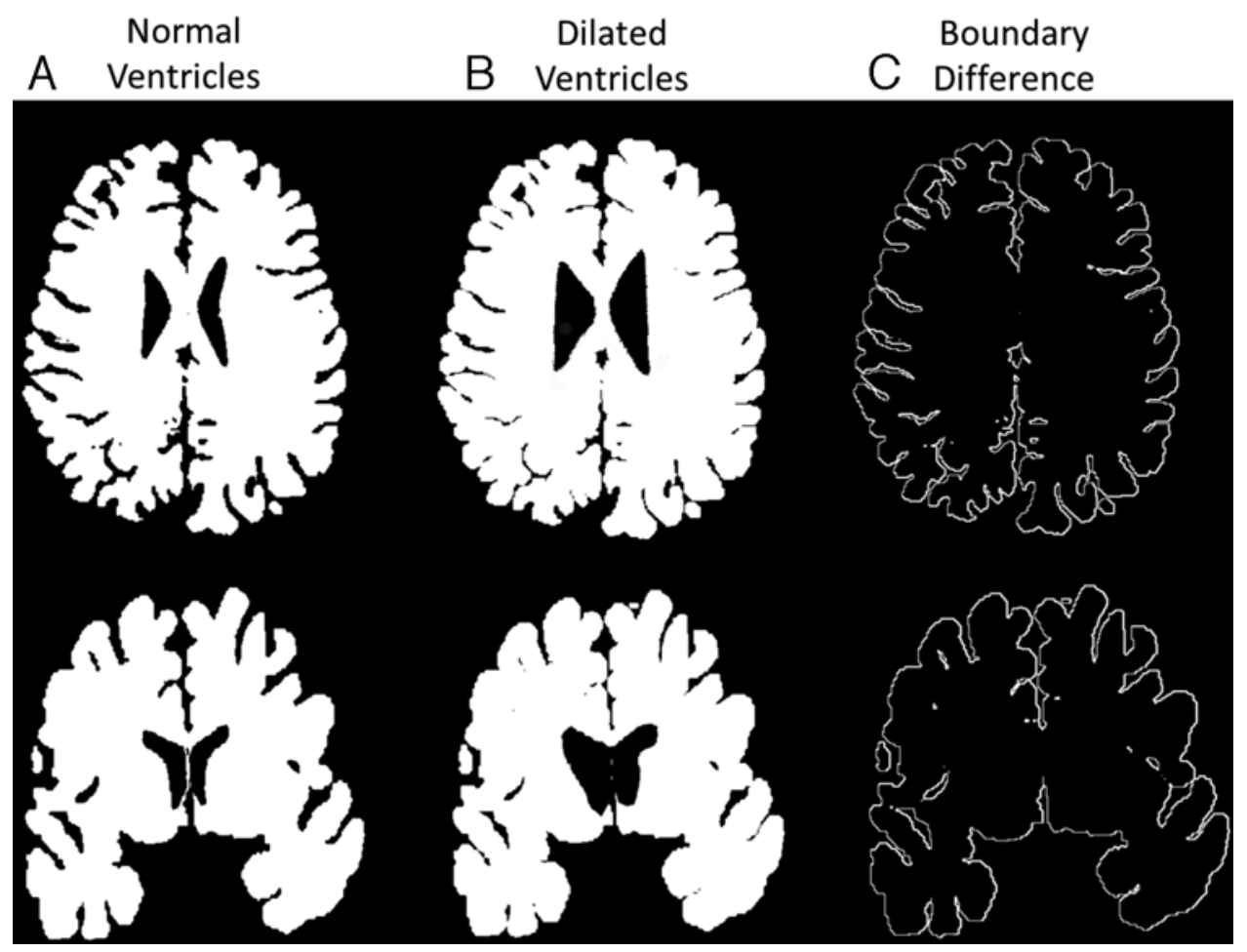

FIG. 5. A hypothetical ventricular expansion is shown on transverse and coronal sections following a 1-mm cortical shift. A 3D binary mask of the cortex has an isotropic voxel size of $1 \times 1 \times 1 \mathrm{~mm}$. A: A 3D binary mask prior to 1-mm cortical shift. After computing the distance map, the voxels with an intensity $\geq 1$ (i.e., $1 \mathrm{~mm}$ from the cortical surface) are added, and a new mask is created. B: The total volume increase amounted to $185.9 \mathrm{ml}$. This change in size means that ventricular enlargement may be accommodated via small expansions of the cortical surface. C: The "Boundary Difference" shows the 1-mm increase in cortical surface between the "Normal" and "Dilated" brain. This small shift is hardly detectable in MRI scans due to limited image resolution.

The incorporation of osmotic gradients and water exchange through AQP channels helps drive the ultimate shifts in fluid that form the basis of the disease process of hydrocephalus. Osmolarity differences also link the CSF compartment to the vascular system. A significant improvement in current hydrocephalus models concerns the incorporation of the cerebral vasculature. There is experimental evidence that has demonstrated blood perfusion changes in hydrocephalus ${ }^{32,79,99}$ However, quantitative models to correlate ICP shifts to changes in blood perfusion are in their infancy. An example of using current image-segmentation techniques for automatic reconstruction of subject-specific cerebrovascular models is shown in Fig. 6. It depicts variations in shape, volume, and articulation of arterial and venous vascular trees between different subjects. Automatic recognition methods of subjectspecific cerebrovascular trees from MR images were used to reconstruct and evaluate the subject-specific angioarchitecture..$^{51}$ Modeling vascular structures in the brain may allow for the incorporation of realistic representations of the cerebral circulation, and especially the capillary bed, in models of hydrocephalus. Real-time subject-specific computational analysis allows the creation of a "brain atlas" for patients, which can play a vital role to help guide diagnosis and treatment for neurological diseases.

A review of the molecular perspective of hydrocephalus points toward the fact that future computational models should integrate molecular water transport shifts and their impact on the well-known ventricular deformation and accumulation of CSF. Combining molecular perspectives with clinical knowledge may help advance the treatment and diagnosis of hydrocephalus. In obstructive hydrocephalus, current treatment involves restoring normal CSF flow, either by removing the obstructive lesion or by creating a bypass of the obstruction. ${ }^{77}$ In primary malabsorptive hydrocephalus, such as in malabsorption at arachnoid villi, shunting of CSF from the brain has been shown to be lifesaving in a disease process that was fatal as little as 65 years ago. ${ }^{77}$ The integration of ICP, ventricular volume, and the relationship of osmolarity to molecular AQP4 pathology is difficult to intuitively align with clinical enlargement of the ventricles, and observed changes in volume and pressure parameters. Use of computational models may potentially help clinicians to better design bypass strategies in noncommunicating hydrocephalus, complement shunt device placement in communicating hydrocephalus, and aid surgical planning for disorders of CSF flow.

\section{Conclusions}

AQP4 channels play an important role in CSF homeostasis and may be a significant factor in diseases of CSF flow. Current effective treatment options for hydrocephalus involve mechanical shunting of CSF, which has many inherent limitations. Mechanical shunts reduce ICP by direct removal of volume. Today, viable and reliable phar- 


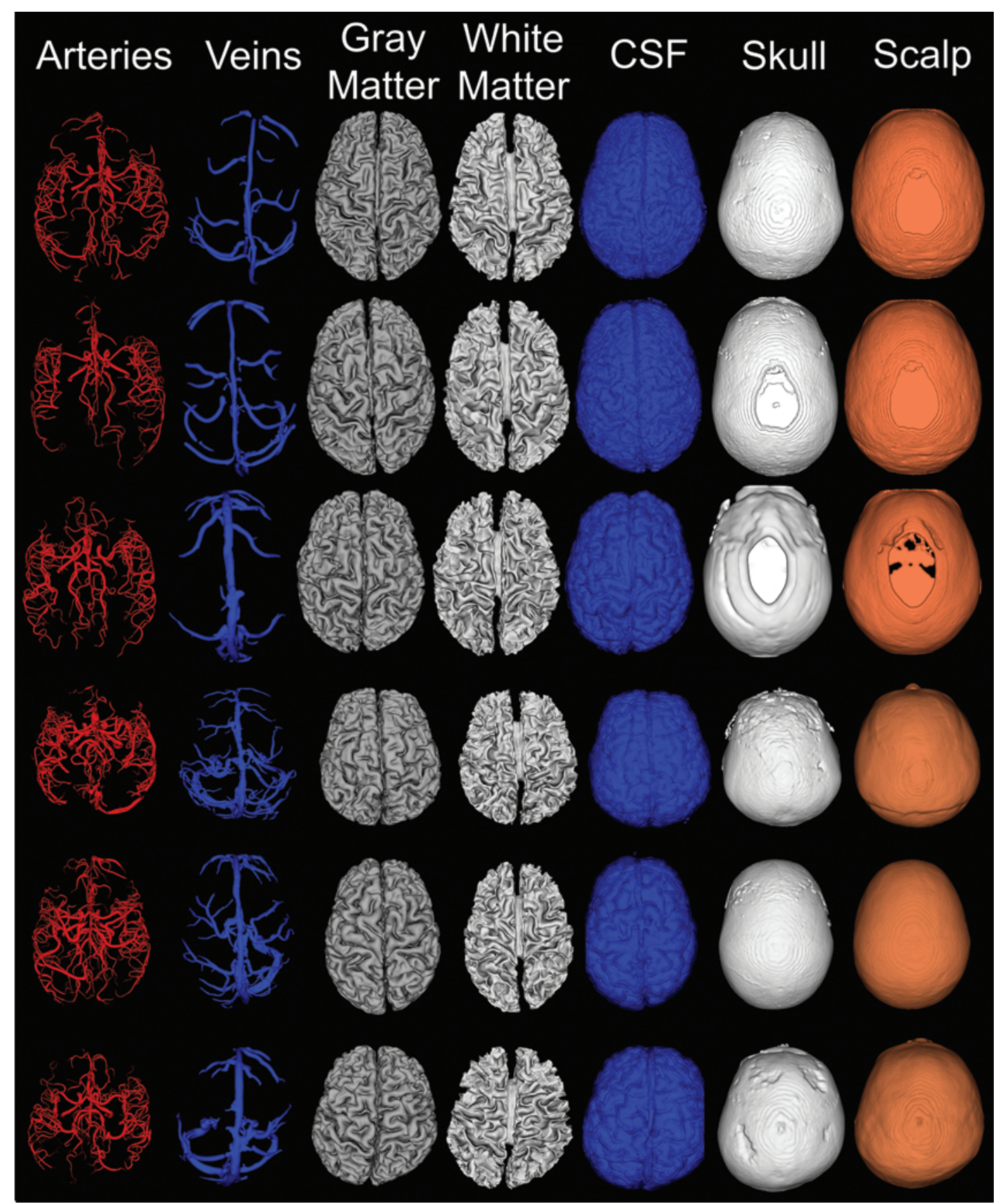

FIG. 6. Image-segmentation techniques are shown for automatic reconstruction of subject-specific cerebrovascular models.

maceutical methods to control the volume of CSF are limited. In the future, it may be possible for molecular shunts to directly modify the flux of brain water through AQP4 channels or by secondarily modifying transcellular osmotic gradients to shift fluid flow.

Ideally, development of a molecular shunt would harness the body's own compensatory upregulation of AQP4 channels to help activate reabsorption of CSF from the ventricles without the need for external fluid diversions. Therefore, modulating the activity of AQP4 channels is an attractive therapeutic target for potential molecular treatment of hydrocephalus. It is imperative that the complex mechanisms of brain water homeostasis continue to be elucidated to appropriately explore these therapeutic molecular targets. Further work into clarifying AQP4 isoforms, promoters, transcription factors, and posttranslational modification methods will help identify the most appropriate therapeutic targets for AQP4 channel modulation.

There are many challenges for the design of therapies that create molecular shunts for hydrocephalus. These include difficulty in creating accurate water-permeation assays, a low hit rate for identification of AQP inhibitors, the small size and pore diameter of AQP channels, and minimal change to AQP channel function with mutations, sug- 
gesting that binding of inhibitors must occur deep within the AQP channel. ${ }^{135}$ However, these challenges are not insurmountable. If efficacious AQP4 modulators are created with minimal neurotoxicity and beneficial pharmacological parameters, they may become useful for treating hydrocephalus at the molecular level without the need for surgical intervention. Further research is needed to identify agents that modulate water flux through AQP4 channels. Pharmacological agents targeting AQPs may pose a viable alternative to help treat hydrocephalus in conjunction with current surgical methods or as a monotherapy when surgery is contraindicated.

More complete models of CSF transport with consideration to absolute ICP, volume, osmolarity, and water flux will help us continue to improve our understanding of the molecular aspects of this complex disease. Although it is clear that ICP is a vital quantity, current computational models are limited in predicting true absolute ICP rise. There is a mismatch between ICP as a clinical quantity and absolute pressure predictions in models, because existing computational models do not account for molecular water exchange at the production or reabsorption level or at the interface between the capillary bed and the interstitial fluid. Moreover, there are no hydrocephalus models that account for osmolarity gradients. Computational models that are able to quantify absolute pressure, volume, and osmolarity changes in line with new evidence are expected to better elucidate the disease process of hydrocephalus.

Although absolute ICP cannot be determined solely by imaging studies, ventricular volume is more accessible. By leveraging volume data through image-segmentation techniques to reconstruct patient MR images into computational models, potential benefits may be derived to promote earlier and more accurate diagnosis of diseases involving CSF-filled spaces. Elevated volume of the ventricular system is a common characteristic of hydrocephalus in numerous types, regardless of measured ICP. Highprecision reconstructions may allow direct comparison of the current size of the ventricular system with previous states of ventricular volumes.

Metrics and shape changes may aid clinicians in determining if the patient is at baseline or beginning to accumulate excess CSF. More precise imaging for diagnosis may potentially allow for earlier treatment of patients with new-onset hydrocephalus. In addition, accurate 3D computational models may help surgical planning for shunt placement. Computational modeling has the potential to demonstrate a variety of clinical benefits, both as a functional tool for physicians to aid diagnosis and treatment of their patients with hydrocephalus, as well as to help clinicians better understand the pathophysiology of the complex molecular interactions of water exchange that occur in hydrocephalus.

\section{Acknowledgments}

Partial support through an Innovator Award (P.I. Andreas Linninger) by the Hydrocephalus Association (directed by Dr. J. Koschnitzky) is gratefully acknowledged.

\section{References}

1. Abe Y, Ikeshima-Kataoka H, Goda W, Niikura T, Yasui M:
An astrocyte-specific enhancer of the aquaporin-4 gene functions through a consensus sequence of POU transcription factors in concert with multiple upstream elements. J Neurochem 120:899-912, 2012

2. Aghayev K, Bal E, Rahimli T, Mut M, Balci S, Vrionis F, et al: Aquaporin-4 expression is not elevated in mild hydrocephalus. Acta Neurochir (Wien) 154:753-759, 2012

3. Agre P, Nielsen S, Ottersen OP: Towards a molecular understanding of water homeostasis in the brain. Neuroscience 129:849-850, 2004

4. Aimard G, Vighetto A, Gabet JY, Bret P, Henry E: [Acetazolamide: an alternative to shunting in normal pressure hydrocephalus? Preliminary results.] Rev Neurol (Paris) 146:437-439, 1990 (Fr)

5. Alikina TY, Zelenin SM, Bondar AA: Theoretical analysis of translational efficiency of the aquaporin 4 mRNA isoforms, in Proceedings of the Third International Conference on Bioinformatics of Genome Regulation and Structures. Novosibirsk, Russia: Institute of Cytology and Genetics, 2002 (http://www.bionet.nsc.ru/meeting/ bgrs_proceedings/pages/bgrs2002.html) [Accessed July 20, 2016]

6. Ambarki K, Lindqvist T, Wåhlin A, Petterson E, Warntjes MJ, Birgander R, et al: Evaluation of automatic measurement of the intracranial volume based on quantitative MR imaging. AJNR Am J Neuroradiol 33:1951-1956, 2012

7. Amiry-Moghaddam M, Frydenlund DS, Ottersen OP: Anchoring of aquaporin-4 in brain: molecular mechanisms and implications for the physiology and pathophysiology of water transport. Neuroscience 129:999-1010, 2004

8. Amiry-Moghaddam M, Ottersen OP: The molecular basis of water transport in the brain. Nat Rev Neurosci 4:991-1001, 2003

9. Assentoft M, Kaptan S, Fenton RA, Hua SZ, de Groot BL, MacAulay N: Phosphorylation of rat aquaporin-4 at Ser ${ }^{111}$ is not required for channel gating. Glia 61:1101-1112, 2013

10. Badaut J, Ashwal S, Adami A, Tone B, Recker R, Spagnoli $\mathrm{D}$, et al: Brain water mobility decreases after astrocytic aquaporin-4 inhibition using RNA interference. J Cereb Blood Flow Metab 31:819-831, 2011

11. Badaut J, Lasbennes F, Magistretti PJ, Regli L: Aquaporins in brain: distribution, physiology, and pathophysiology. J Cereb Blood Flow Metab 22:367-378, 2002

12. Baum BJ, Alevizos I, Zheng C, Cotrim AP, Liu S, McCullagh L, et al: Early responses to adenoviral-mediated transfer of the aquaporin-1 cDNA for radiation-induced salivary hypofunction. Proc Natl Acad Sci U S A 109:1940319407, 2012

13. Baum BJ, Zheng C, Cotrim AP, Goldsmith CM, Atkinson JC, Brahim JS, et al: Transfer of the AQP1 cDNA for the correction of radiation-induced salivary hypofunction. Biochim Biophys Acta 1758: 1071-1077, 2006

14. Bloch O, Auguste KI, Manley GT, Verkman AS: Accelerated progression of kaolin-induced hydrocephalus in aquaporin-4-deficient mice. J Cereb Blood Flow Metab 26:1527-1537, 2006

15. Bloch O, Manley GT: The role of aquaporin-4 in cerebral water transport and edema. Neurosurg Focus 22(5):E3, 2007

16. Brown PN, Jackson PC, Staddon GE, Richardson RB, Griffith HB: Compartmental analysis of cerebrospinal fluid transfer and absorption in simulated hydrocephalus. Phys Med Biol 30:1113-1121, 1985

17. Buishas J, Gould IG, Linninger AA: A computational model of cerebrospinal fluid production and reabsorption driven by Starling forces. Croat Med J 55:481-497, 2014

18. Cabanes J, Marti J, Orozco M, Beltran A: Bicompartmental analysis of cerebrospinal fluid circulation. Theory and clinical applications. J Neurosurg 59:311-321, 1983 
19. Cacabelos R, Barquero M, García P, Alvarez XA, Varela de Seijas E: Cerebrospinal fluid interleukin-1 beta (IL-1 beta) in Alzheimer's disease and neurological disorders. Methods Find Exp Clin Pharmacol 13:455-458, 1991

20. Carmosino M, Procino G, Tamma G, Mannucci R, Svelto M, Valenti G: Trafficking and phosphorylation dynamics of AQP4 in histamine-treated human gastric cells. Biol Cell 99:25-36, 2007

21. Castañeyra-Ruiz L, González-Marrero I, González-Toledo JM, Castañeyra-Ruiz A, de Paz-Carmona H, CastañeyraPerdomo A, et al: Aquaporin-4 expression in the cerebrospinal fluid in congenital human hydrocephalus. Fluids Barriers CNS 10:18, 2013

22. Cheng S, Jacobson E, Bilston LE: Models of the pulsatile hydrodynamics of cerebrospinal fluid flow in the normal and abnormal intracranial system. Comput Methods Biomech Biomed Engin 10:151-157, 2007

23. Clarke MJ, Meyer FB: The history of mathematical modeling in hydrocephalus. Neurosurg Focus 22(4):E3, 2007

24. Cutler RW, Page L, Galicich J, Watters GV: Formation and absorption of cerebrospinal fluid in man. Brain 91:707720,1968

25. Davuluri RV, Suzuki Y, Sugano S, Plass C, Huang THM: The functional consequences of alternative promoter use in mammalian genomes. Trends Genet 24:167-177, 2008

26. De Bellis M, Pisani F, Mola MG, Basco D, Catalano F, Nicchia GP, et al: A novel human aquaporin-4 splice variant exhibits a dominant-negative activity: a new mechanism to regulate water permeability. Mol Biol Cell 25:470-480, 2014

27. Del Bigio MR: Neuropathology and structural changes in hydrocephalus. Dev Disabil Res Rev 16:16-22, 2010

28. Del Bigio MR, Di Curzio DL: Nonsurgical therapy for hydrocephalus: a comprehensive and critical review. Fluids Barriers CNS 13:3, 2016

29. Del Bigio MR, Enno TL: Effect of hydrocephalus on rat brain extracellular compartment. Cerebrospinal Fluid Res 5:12, 2008

30. Dey M, Stadnik A, Riad F, Zhang L, McBee N, Kase C, et al: Bleeding and infection with external ventricular drainage: a systematic review in comparison with adjudicated adverse events in the ongoing Clot Lysis Evaluating Accelerated Resolution of Intraventricular Hemorrhage Phase III (CLEAR-III IHV) trial. Neurosurgery 76:291-301, 2015

31. Diringer MN, Edwards DF, Zazulia AR: Hydrocephalus: a previously unrecognized predictor of poor outcome from supratentorial intracerebral hemorrhage. Stroke 29:13521357, 1998

32. Dombrowski SM, Schenk S, Leichliter A, Leibson Z, Fukamachi K, Luciano MG: Chronic hydrocephalus-induced changes in cerebral blood flow: mediation through cardiac effects. J Cereb Blood Flow Metab 26:1298-1310, 2006

33. Engel A, Fujiyoshi Y, Gonen T, Walz T: Junction-forming aquaporins. Curr Opin Struct Biol 18:229-235, 2008

34. Feng X, Papadopoulos MC, Liu J, Li L, Zhang D, Zhang H, et al: Sporadic obstructive hydrocephalus in Aqp4 null mice. J Neurosci Res 87:1150-1155, 2009

35. Fenton RA, Moeller HB, Zelenina M, Snaebjornsson MT, Holen T, MacAulay N: Differential water permeability and regulation of three aquaporin 4 isoforms. Cell Mol Life Sci 67:829-840, 2010

36. Ferreira CB, Bassi E, Lucena L, Carreta H, Miranda LC, Tierno PF, et al: Measurement of intracranial pressure and short-term outcomes of patients with traumatic brain injury: a propensity-matched analysis. Rev Bras Ter Intensiva 27:315-321, 2015

37. Filippidis AS, Kalani MY, Rekate HL: Hydrocephalus and aquaporins: lessons learned from the bench. Childs Nerv Syst 27:27-33, 2011
38. Frydenlund DS, Bhardwaj A, Otsuka T, Mylonakou MN Yasumura T, Davidson KG, et al: Temporary loss of perivascular aquaporin-4 in neocortex after transient middle cerebral artery occlusion in mice. Proc Natl Acad Sci U S A 103:13532-13536, 2006

39. Furman CS, Gorelick-Feldman DA, Davidson KGV, Yasumura T, Neely JD, Agre P, et al: Aquaporin-4 square array assembly: opposing actions of M1 and M23 isoforms. Proc Natl Acad Sci U S A 100: 13609-13614, 2003

40. Galarza M, Giménez Á, Valero J, Pellicer OP, Amigó JM: Computational fluid dynamics of ventricular catheters used for the treatment of hydrocephalus: a 3D analysis. Childs Nerv Syst 30:105-116, 2014

41. Gao F, Liu F, Chen Z, Hua Y, Keep RF, Xi G: Hydrocephalus after intraventricular hemorrhage: the role of thrombin. J Cereb Blood Flow Metab 34:489-494, 2014

42. Gao F, Zheng M, Hua Y, Keep RF, Xi G: Acetazolamide attenuates thrombin-induced hydrocephalus. Acta Neurochir Suppl 121:373-377, 2016

43. Gao R, Yan X, Zheng C, Goldsmith CM, Afione S, Hai B, et al: AAV2-mediated transfer of the human aquaporin-1 cDNA restores fluid secretion from irradiated miniature pig parotid glands. Gene Ther 18:38-42, 2011

44. Gómez DG, DiBenedetto AT, Pavese AM, Firpo A, Hershan DB, Potts DG: Development of arachnoid villi and granulations in man. Acta Anat (Basel) 111:247-258, 1982

45. Gunnarson E, Axehult G, Baturina G, Zelenin S, Zelenina M, Aperia A: Lead induces increased water permeability in astrocytes expressing aquaporin 4 . Neuroscience 136:105114,2005

46. Gunnarson E, Zelenina M, Axehult G, Song Y, Bondar A, Krieger P, et al: Identification of a molecular target for glutamate regulation of astrocyte water permeability. Glia 56:587-596, 2008

47. Hayden PW, Foltz EL, Shurtleff DB: Effect of on oral osmotic agent on ventricular fluid pressure of hydrocephalic children. Pediatrics 41:955-967, 1968

48. Hiroaki Y, Tani K, Kamegawa A, Gyobu N, Nishikawa K, Suzuki H, et al: Implications of the aquaporin-4 structure on array formation and cell adhesion. J Mol Biol 355:628-639, 2006

49. Hodel J, Besson P, Rahmouni A, Petit E, Lebret A, Grandjacques B, et al: 3D mapping of cerebrospinal fluid local volume changes in patients with hydrocephalus treated by surgery: preliminary study. Eur Radiol 24:136-142, 2014

50. Hodel J, Lebret A, Petit E, Leclerc X, Zins M, Vignaud A, et al: Imaging of the entire cerebrospinal fluid volume with a multistation 3D SPACE MR sequence: feasibility study in patients with hydrocephalus. Eur Radiol 23:1450-1458, 2013

51. Hsu CY, Schneller B, Alaraj A, Flannery M, Zhou XJ, Linninger A: Automatic recognition of subject-specific cerebrovascular trees. Magn Reson Med [epub ahead of print], 2016

52. Hsu MS, Seldin M, Lee DJ, Seifert G, Steinhäuser C, Binder DK: Laminar-specific and developmental expression of aquaporin-4 in the mouse hippocampus. Neuroscience 178:21-32, 2011

53. Hsu Y, Tran M, Linninger AA: Dynamic regulation of aquaporin-4 water channels in neurological disorders. Croat Med J 56:401-421, 2015

54. Huber VJ, Tsujita M, Kwee IL, Nakada T: Inhibition of aquaporin 4 by antiepileptic drugs. Bioorg Med Chem 17:418-424, 2009

55. Huber VJ, Tsujita M, Yamazaki M, Sakimura K, Nakada T: Identification of arylsulfonamides as aquaporin 4 inhibitors. Bioorg Med Chem Lett 17:1270-1273, 2007

56. Igarashi H, Tsujita M, Kwee IL, Nakada T: Water influx into 
cerebrospinal fluid is primarily controlled by aquaporin-4, not by aquaporin-1: 170 JJVCPE MRI study in knockout mice. Neuroreport 25:39-43, 2014

57. Iliff JJ, Wang M, Liao Y, Plogg BA, Peng W, Gundersen GA, et al: A paravascular pathway facilitates CSF flow through the brain parenchyma and the clearance of interstitial solutes, including amyloid $\beta$. Sci Transl Med 4:147ra111, 2012

58. Ishii K, Soma T, Shimada K, Oda H, Terashima A, Kawasaki R: Automatic volumetry of the cerebrospinal fluid space in idiopathic normal pressure hydrocephalus. Dement Geriatr Cogn Dis Extra 3:489-496, 2013

59. Ito $\mathrm{H}$, Yamamoto $\mathrm{N}$, Arima $\mathrm{H}$, Hirate $\mathrm{H}$, Morishima $\mathrm{T}$, Umenishi $\mathrm{F}$, et al: Interleukin- $1 \beta$ induces the expression of aquaporin- 4 through a nuclear factor- $\kappa \mathrm{B}$ pathway in rat astrocytes. J Neurochem 99: 107-118, 2006

60. Ivkovic M, Reiss-Zimmermann M, Katzen H, Preuss M, Kovanlikaya I, Heier L, et al: MRI assessment of the effects of acetazolamide and external lumbar drainage in idiopathic normal pressure hydrocephalus. Fluids Barriers CNS 12:9, 2015

61. Kadohira I, Abe Y, Nuriya M, Sano K, Tsuji S, Arimitsu T, et al: Phosphorylation in the C-terminal domain of aquaporin-4 is required for Golgi transition in primary cultured astrocytes. Biochem Biophys Res Commun 377:463-468, 2008

62. Kamali-Zare P, Nicholson C: Brain extracellular space: geometry, matrix and physiological importance. Basic Clin Neurosci 4:282-286, 2013

63. Kato J, Hayashi MK, Aizu S, Yukutake Y, Takeda J, Yasui M: A general anaesthetic propofol inhibits aquaporin-4 in the presence of $\mathrm{Zn}^{2+}$. Biochem J 454:275-282, 2013

64. Ke C, Poon WS, Ng HK, Pang JCS, Chan Y: Heterogeneous responses of aquaporin-4 in oedema formation in a replicated severe traumatic brain injury model in rats. Neurosci Lett 301:21-24, 2001

65. Kimelberg HK: Current concepts of brain edema. Review of laboratory investigations. J Neurosurg 83:1051-1059, 1995

66. Kitchen P, Day RE, Taylor LHJ, Salman MM, Bill RM, Conner MT, et al: Identification and molecular mechanisms of the rapid tonicity-induced relocalization of the aquaporin 4 channel. J Biol Chem 290:16873-16881, 2015

67. Klarica M, Miše B, Vladić A, Radoš M, Orešković D: "Compensated hyperosmolarity" of cerebrospinal fluid and the development of hydrocephalus. Neuroscience 248:278289, 2013

68. Kleindienst A, Fazzina G, Amorini AM, Dunbar JG, Glisson $\mathrm{R}$, Marmarou A: Modulation of AQP4 expression by the protein kinase $\mathrm{C}$ activator, phorbol myristate acetate, decreases ischemia-induced brain edema. Acta Neurochir Suppl 96:393-397, 2006

69. Kong H, Fan Y, Xie J, Ding J, Sha L, Shi X, et al: AQP4 knockout impairs proliferation, migration and neuronal differentiation of adult neural stem cells. J Cell Sci 121:40294036, 2008

70. Krishnamurthy S, Li J, Schultz L, Jenrow KA: Increased CSF osmolarity reversibly induces hydrocephalus in the normal rat brain. Fluids Barriers CNS 9:13, 2012

71. Krishnamurthy S, Li J, Schultz L, McAllister JP II: Intraventricular infusion of hyperosmolar dextran induces hydrocephalus: a novel animal model of hydrocephalus. Cerebrospinal Fluid Res 6:16, 2009

72. Kuwahara-Otani S, Maeda S, Tanaka K, Hayakawa T, Seki M: Systemic administration of lipopolysaccharide increases the expression of aquaporin- 4 in the rat anterior pituitary gland. J Vet Med Sci 75:1081-1084, 2013

73. Lee P, Monaco EA III, Friedlander RM: Blocking TGF- $\beta$ activity and associated inflammation may halt hydrocephalus. Neurosurgery 73:N13-N14, 2013
74. Lee SC, Lueck CJ: Cerebrospinal fluid pressure in adults. J Neuroophthalmol 34:278-283, 2014

75. Li X, Kong H, Wu W, Xiao M, Sun X, Hu G: Aquaporin-4 maintains ependymal integrity in adult mice. Neuroscience 162:67-77, 2009

76. Linninger AA, Sweetman B, Penn R: Normal and hydrocephalic brain dynamics: the role of reduced cerebrospinal fluid reabsorption in ventricular enlargement. Ann Biomed Eng 37: 1434-1447, 2009

77. Linninger AA, Tangen K, Hsu CY, Frim D: Cerebrospinal fluid mechanics and its coupling to cerebrovascular dynamics. Annu Rev Fluid Mech 48:219-257, 2016

78. Linninger AA, Xenos M, Sweetman B, Ponkshe S, Guo X, Penn R: A mathematical model of blood, cerebrospinal fluid and brain dynamics. J Math Biol 59:729-759, 2009

79. Luciano M, Dombrowski S: Hydrocephalus and the heart: interactions of the first and third circulations. Cleve Clin J Med 74 (Suppl 1):S128-S131, 2007

80. Madrid R, Le Maout S, Barrault MB, Janvier K, Benichou $\mathrm{S}$, Mérot J: Polarized trafficking and surface expression of the AQP4 water channel are coordinated by serial and regulated interactions with different clathrin-adaptor complexes. EMBO J 20:7008-7021, 2001

81. Mao X, Enno TL, Del Bigio MR: Aquaporin 4 changes in rat brain with severe hydrocephalus. Eur J Neurosci 23:2929-2936, 2006

82. Mealey J Jr, Barker DT: Failure of oral acetazolamide to avert hydrocephalus in infants with myelomeningocele. J Pediatr 72:257-259, 1968

83. Mercuri E, Faundez JC, Cowan F, Dubowitz L: Acetazolamide without frusemide in the treatment of posthaemorrhagic hydrocephalus. Acta Paediatr 83:1319-1321, 1994

84. Migliati E, Meurice N, DuBois P, Fang JS, Somasekharan $\mathrm{S}$, Beckett E, et al: Inhibition of aquaporin-1 and aquaporin-4 water permeability by a derivative of the loop diuretic bumetanide acting at an internal pore-occluding binding site. Mol Pharmacol 76:105-112, 2009

85. Miner ME: Acetazolamide treatment of progressive hydrocephalus secondary to intraventricular hemorrhage in a preterm infant. Childs Nerv Syst 2:105-106, 1986

86. Mobasheri A, Marples D, Young IS, Floyd RV, Moskaluk CA, Frigeri A: Distribution of the AQP4 water channel in normal human tissues: protein and tissue microarrays reveal expression in several new anatomical locations, including the prostate gland and seminal vesicles. Channels (Austin) 1:29-38, 2007

87. Moe SE, Sorbo JG, Sogaard R, Zeuthen T, Petter Ottersen $\mathrm{O}$, Holen T: New isoforms of rat aquaporin-4. Genomics 91:367-377, 2008

88. Moeller HB, Fenton RA, Zeuthen T, Macaulay N: Vasopressin-dependent short-term regulation of aquaporin 4 expressed in Xenopus oocytes. Neuroscience 164:16741684, 2009

89. Neely JD, Amiry-Moghaddam M, Ottersen OP, Froehner SC, Agre P, Adams ME: Syntrophin-dependent expression and localization of aquaporin-4 water channel protein. Proc Natl Acad Sci U S A 98: 14108-14113, 2001

90. Neely JD, Christensen BM, Nielsen S, Agre P: Heterotetrameric composition of aquaporin-4 water channels. Biochemistry 38:11156-11163, 1999

91. Nicchia GP, Frigeri A, Liuzzi GM, Svelto M: Inhibition of aquaporin- 4 expression in astrocytes by RNAi determines alteration in cell morphology, growth, and water transport and induces changes in ischemia-related genes. FASEB J 17:1508-1510, 2003

92. Nielsen S, Nagelhus EA, Amiry-Moghaddam M, Bourque C, Agre P, Ottersen OP: Specialized membrane domains for water transport in glial cells: high-resolution immuno- 
gold cytochemistry of aquaporin-4 in rat brain. J Neurosci 17:171-180, 1997

93. Niemietz CM, Tyerman SD: New potent inhibitors of aquaporins: silver and gold compounds inhibit aquaporins of plant and human origin. FEBS Lett 531:443-447, 2002

94. Oku H, Morishita S, Horie T, Kida T, Mimura M, Fukumoto $M$, et al: Nitric oxide increases the expression of aquaporin-4 protein in rat optic nerve astrocytes through the cyclic guanosine monophosphate/protein kinase $\mathrm{G}$ pathway. Ophthalmic Res 54:212-221, 2015

95. Oshio K, Song Y, Verkman AS, Manley GT: Aquaporin-1 deletion reduces osmotic water permeability and cerebrospinal fluid production. Acta Neurochir Suppl 86:525-528, 2003

96. Oshio K, Watanabe H, Song Y, Verkman AS, Manley GT: Reduced cerebrospinal fluid production and intracranial pressure in mice lacking choroid plexus water channel aquaporin-1. FASEB J 19:76-78, 2005

97. Pan CF, Zhu SM, Zheng YY: Ammonia induces upregulation of aquaporin-4 in neocortical astrocytes of rats through the p38 mitogen-activated protein kinase pathway. Chin Med J (Engl) 123:1888-1892, 2010

98. Papadopoulos MC, Verkman AS: Potential utility of aquaporin modulators for therapy of brain disorders. Prog Brain Res 170:589-601, 2008

99. Park EH, Dombrowski S, Luciano M, Zurakowski D, Madsen JR: Alterations of pulsation absorber characteristics in experimental hydrocephalus. J Neurosurg Pediatr 6:159-170, 2010

100. Paul L, Madan M, Rammling M, Chigurupati S, Chan SL, Pattisapu JV: Expression of aquaporin 1 and 4 in a congenital hydrocephalus rat model. Neurosurgery 68:462-473, 2011

101. Penn RD, Basati S, Sweetman B, Guo X, Linninger A: Ventricle wall movements and cerebrospinal fluid flow in hydrocephalus. J Neurosurg 115:159-164, 2011

102. Piper RJ, Kalyvas AV, Young AM, Hughes MA, Jamjoom AA, Fouyas IP: Interventions for idiopathic intracranial hypertension. Cochrane Database Syst Rev 8:CD003434, 2015

103. Pisani F, Rossi A, Nicchia GP, Svelto M, Frigeri A: Translational regulation mechanisms of aquaporin-4 supramolecular organization in astrocytes. Glia 59:1923-1932, 2011

104. Poca MA, Sahuquillo J: Short-term medical management of hydrocephalus. Expert Opin Pharmacother 6:1525-1538, 2005

105. Qi LL, Fang SH, Shi WZ, Huang XQ, Zhang XY, Lu YB, et al: CysLT2 receptor-mediated AQP4 up-regulation is involved in ischemic-like injury through activation of ERK and p38 MAPK in rat astrocytes. Life Sci 88:50-56, 2011

106. Ramakrishna R, Sekhar LN, Ramanathan D, Temkin N, Hallam D, Ghodke BV, et al: Intraventricular tissue plasminogen activator for the prevention of vasospasm and hydrocephalus after aneurysmal subarachnoid hemorrhage. Neurosurgery 67:110-117, 2010

107. Rash JE, Davidson KGV, Yasumura T, Furman CS: Freezefracture and immunogold analysis of aquaporin-4 (AQP4) square arrays, with models of AQP4 lattice assembly. Neuroscience 129:915-934, 2004

108. Ratelade J, Verkman AS: Neuromyelitis optica: aquaporin-4 based pathogenesis mechanisms and new therapies. Int $\mathbf{J}$ Biochem Cell Biol 44:1519-1530, 2012

109. Reddy GK, Bollam P, Caldito G: Long-term outcomes of ventriculoperitoneal shunt surgery in patients with hydrocephalus. World Neurosurg 81:404-410, 2014

110. Ribeiro MdeC, Hirt L, Bogousslavsky J, Regli L, Badaut J: Time course of aquaporin expression after transient focal cerebral ischemia in mice. J Neurosci Res 83:1231-1240, 2006
111. Rossi A, Baumgart F, van Hoek AN, Verkman AS: PostGolgi supramolecular assembly of aquaporin-4 in orthogonal arrays. Traffic 13:43-53, 2012

112. Rossi A, Crane JM, Verkman AS: Aquaporin-4 Mz isoform: brain expression, supramolecular assembly and neuromyelitis optica antibody binding. Glia 59:1056-1063, 2011

113. Sadlish H, Pitonzo D, Johnson AE, Skach WR: Sequential triage of transmembrane segments by Sec61alpha during biogenesis of a native multispanning membrane protein. Nat Struct Mol Biol 12:870-878, 2005

114. Sæhle T, Eide PK: Intracranial pressure monitoring in pediatric and adult patients with hydrocephalus and tentative shunt failure: a single-center experience over 10 years in 146 patients. J Neurosurg 122:1076-1086, 2015

115. Salminen LE, Conturo TE, Bolzenius JD, Cabeen RP, Akbudak E, Paul RH: Reducing CSF partial volume effects to enhance diffusion tensor imaging metrics of brain microstructure. Technol Innov 18:5-20, 2016

116. Shen XQ, Miyajima M, Ogino I, Arai H: Expression of the water-channel protein aquaporin 4 in the H-Tx rat: possible compensatory role in spontaneously arrested hydrocephalus. J Neurosurg 105 (6 Suppl):459-464, 2006

117. Shoesmith CL, Buist R, Del Bigio MR: Magnetic resonance imaging study of extracellular fluid tracer movement in brains of immature rats with hydrocephalus. Neurol Res 22:111-116, 2000

118. Silberstein C, Bouley R, Huang Y, Fang P, Pastor-Soler N, Brown D, et al: Membrane organization and function of M1 and M23 isoforms of aquaporin-4 in epithelial cells. Am J Physiol Renal Physiol 287:F501-F511, 2004

119. Skjolding AD, Rowland IJ, Søgaard LV, Praetorius J, Penkowa M, Juhler M: Hydrocephalus induces dynamic spatiotemporal regulation of aquaporin-4 expression in the rat brain. Cerebrospinal Fluid Res 7:20, 2010

120. Smith QR, Johanson CE: Effect of carbonic anhydrase inhibitors and acidosis in choroid plexus epithelial cell sodium and potassium. J Pharmacol Exp Ther 215:673-680, 1980

121. Solenov E, Watanabe H, Manley GT, Verkman AS: Sevenfold-reduced osmotic water permeability in primary astrocyte cultures from AQP-4-deficient mice, measured by a fluorescence quenching method. Am J Physiol Cell Physiol 286:C426-C432, 2004

122. Spector R, Keep RF, Robert Snodgrass S, Smith QR, Johanson CE: A balanced view of choroid plexus structure and function: focus on adult humans. Exp Neurol 267:7886,2015

123. Supuran CT: Acetazolamide for the treatment of idiopathic intracranial hypertension. Expert Rev Neurother 15:851856,2015

124. Suzuki H, Nishikawa K, Hiroaki Y, Fujiyoshi Y: Formation of aquaporin-4 arrays is inhibited by palmitoylation of N-terminal cysteine residues. Biochim Biophys Acta 1778: 1181-1189, 2008

125. Swenson ER: Pharmacology of acute mountain sickness: old drugs and newer thinking. J Appl Physiol (1985) 120:204-215, 2016

126. Tait MJ, Saadoun S, Bell BA, Papadopoulos MC: Water movements in the brain: role of aquaporins. Trends Neurosci 31:37-43, 2008

127. Tarkowski E, Tullberg M, Fredman P, Wikkelsö C: Normal pressure hydrocephalus triggers intrathecal production of TNF-alpha. Neurobiol Aging 24:707-714, 2003

128. Thrane AS, Rappold PM, Fujita T, Torres A, Bekar LK, Takano T, et al: Critical role of aquaporin-4 (AQP4) in astrocytic $\mathrm{Ca} 2+$ signaling events elicited by cerebral edema. Proc Natl Acad Sci U S A 108:846-851, 2011

129. Tomás-Camardiel M, Venero JL, Herrera AJ, De Pablos RM, Pintor-Toro JA, Machado A, et al: Blood-brain barrier 
disruption highly induces aquaporin-4 mRNA and protein in perivascular and parenchymal astrocytes: protective effect by estradiol treatment in ovariectomized animals. J Neurosci Res 80:235-246, 2005

130. Tourdias T, Dragonu I, Fushimi Y, Deloire MS, Boiziau C, Brochet B, et al: Aquaporin 4 correlates with apparent diffusion coefficient and hydrocephalus severity in the rat brain: a combined MRI-histological study. Neuroimage 47:659666, 2009

131. Umenishi F, Verkman AS: Isolation and functional analysis of alternative promoters in the human aquaporin-4 water channel gene. Genomics 50:373-377, 1998

132. van Meer G, Vaz WL: Membrane curvature sorts lipids. Stabilized lipid rafts in membrane transport. EMBO Rep 6:418-419, 2005

133. Venero JL, Machado A, Cano J: Importance of aquaporins in the physiopathology of brain edema. Curr Pharm Des 10:2153-2161, 2004

134. Venero JL, Vizuete ML, Machado A, Cano J: Aquaporins in the central nervous system. Prog Neurobiol 63:321-336, 2001

135. Verkman AS, Anderson MO, Papadopoulos MC: Aquaporins: important but elusive drug targets. Nat Rev Drug Discov 13:259-277, 2014

136. Verkman AS, Binder DK, Bloch O, Auguste K, Papadopoulos MC: Three distinct roles of aquaporin-4 in brain function revealed by knockout mice. Biochim Biophys Acta 1758:1085-1093, 2006

137. Wen H, Nagelhus EA, Amiry-Moghaddam M, Agre P, Ottersen OP, Nielsen S: Ontogeny of water transport in rat brain: postnatal expression of the aquaporin-4 water channel. Eur J Neurosci 11:935-945, 1999

138. Winning RS, Shea LJ, Marcus SJ, Sargent TD: Developmental regulation of transcription factor AP-2 during Xenopus laevis embryogenesis. Nucleic Acids Res 19:3709-3714, 1991

139. Wu Y, Green NL, Wrensch MR, Zhao S, Gupta N: Ventriculoperitoneal shunt complications in California: 1990 to 2000. Neurosurgery 61:557563, 2007

140. Yool AJ: Aquaporins: multiple roles in the central nervous system. Neuroscientist 13:470-485, 2007

141. Zelenin S, Gunnarson E, Alikina T, Bondar A, Aperia A: Identification of a new form of AQP4 mRNA that is developmentally expressed in mouse brain. Pediatr Res 48:335339,2000
142. Zelenina M, Zelenin S, Bondar AA, Brismar H, Aperia A: Water permeability of aquaporin-4 is decreased by protein kinase $\mathrm{C}$ and dopamine. Am J Physiol Renal Physiol 283:F309-F318, 2002

143. Zhang H, Verkman AS: Evidence against involvement of aquaporin-4 in cell-cell adhesion. J Mol Biol 382:11361143,2008

144. Zhao J, Moore AN, Clifton GL, Dash PK: Sulforaphane enhances aquaporin-4 expression and decreases cerebral edema following traumatic brain injury. J Neurosci Res 82:499-506, 2005

145. Zheng GQ, Li Y, Gu Y, Chen XM, Zhou Y, Zhao SZ, et al: Beyond water channel: aquaporin-4 in adult neurogenesis. Neurochem Int 56:651-654, 2010

146. Ziai WC, Tuhrim S, Lane K, McBee N, Lees K, Dawson J, et al: A multicenter, randomized, double-blinded, placebocontrolled phase III study of Clot Lysis Evaluation of Accelerated Resolution of Intraventricular Hemorrhage (CLEAR III). Int J Stroke 9:536-542, 2014

\section{Disclosures}

The authors report no conflict of interest concerning the materials or methods used in this study or the findings specified in this paper.

\section{Author Contributions}

Conception and design: Linninger, Desai, Mehta. Acquisition of data: Linninger, Desai, Hsu, Schneller. Analysis and interpretation of data: Desai, Hsu, Schneller, Hobbs. Drafting the article: Desai, Hsu, Mehta. Critically revising the article: Linninger, Desai, Hsu, Hobbs, Mehta. Reviewed submitted version of manuscript: Desai, Hsu, Hobbs, Mehta. Approved the final version of the manuscript on behalf of all authors: Linninger. Statistical analysis: Mehta. Administrative/technical/material support: Linninger, Schneller. Study supervision: Desai.

\section{Correspondence}

Andreas A. Linninger, University of Illinois at Chicago, 912 South Wood St., M/C 799 4N NPI, Chicago, IL 60612. email: linninge@uic.edu. 